\title{
Cambios en la producción y consumo de viandas en Cuba
}

Un acercamiento a la experiencia de los habitantes en Güira de Melena

Changements dans la production et la consommation des viandas à Cuba:

approche de l'expérience des habitants de Güira de Melena

\section{Norma Helen Juárez}

\section{CpenEdition}

\section{Journals}

\section{Edición electrónica}

URL: http://journals.openedition.org/ethnoecologie/1445

DOI: 10.4000/ethnoecologie. 1445

ISSN: 2267-2419

\section{Editor}

Laboratoire Eco-anthropologie et Ethnobiologie

\section{Referencia electrónica}

Norma Helen Juárez, « Cambios en la producción y consumo de viandas en Cuba », Revue d'ethnoécologie [En ligne], 3 | 2013, mis en ligne le 12 novembre 2013, consulté le 19 avril 2019. URL : http://journals.openedition.org/ethnoecologie/1445; DOI : 10.4000/ethnoecologie.1445

Este documento fue generado automáticamente el 19 abril 2019.

Revue d'ethnoécologie est mis à disposition selon les termes de la licence Creative Commons Attribution - Pas d'Utilisation Commerciale - Pas de Modification 4.0 International. 


\title{
Cambios en la producción y consumo de viandas en Cuba
}

\author{
Un acercamiento a la experiencia de los habitantes en Güira de Melena \\ Changements dans la production et la consommation des viandas à Cuba: \\ approche de l'expérience des habitants de Güira de Melena
}

Norma Helen Juárez

\section{Una aproximación al consumo de viandas ${ }^{1}$ desde una perspectiva etnoecológica}

Desde sus inicios en la década de 1950, la etnoecología ha desarrollado un amplio rango de enfoques; desde un entendimiento cultural de las relaciones entre organismos hasta un enfoque aplicado que se centra en la utilidad de tal conocimiento para el desarrollo de la comunidad y el manejo de los recursos de la misma (Beaucage 1997). Algunos autores incluyen también los aspectos cognitivos y simbólicos inmersos en las prácticas asociadas a los organismos y sus interrelaciones (Toledo 1992, 2009) Con el tiempo, la etnoecología ha evolucionado de un determinismo ambiental a enfoques que integran elementos que van desde la antropología cognitiva, hasta aspectos de ecología política (Reyes \& Martí 2007).

2 Si bien hay una gran diversidad de enfoques, la etnoecología se puede entender de manera general como el conocimiento espontáneo, culturalmente referenciado sobre la naturaleza, dirigido a la resolución de situaciones cuotidianas (Souza \& Da Silva 2006). Algunas de las principales líneas de investigación en etnoecología giran entorno a :1) los sistemas locales de conocimiento ecológico, 2) las relaciones entre diversidad biológica y diversidad cultural, 3) los sistemas de manejo de los recursos naturales y 4) las relaciones entre desarrollo económico y bienestar humano (ibídem). Es en esta última línea de investigación, donde se ha logrado incorporar elementos de la antropología, la ciencia política y la economía. Un ejemplo cercano a esta perspectiva, es el estudio de caso 
realizado por Esther Katz en la Mixteca Alta del Estado de Oaxaca México, en donde el fenómeno de la emigración, y la implementación de programas de desarrollo impulsados por el gobierno han traído consigo, un cambio tanto en la preparación como en las preferencias de los alimentos. Desde el momento en que las familias son receptoras de remesas del extranjero, el consumo de carne se ha incrementado, mientras que los productos frescos como verduras y alimentos silvestres de recolección, disminuyen, para ser sustituidos por productos procesados (Katz 2009).

3 Si bien la etnoecología como disciplina nos ha permitido profundizar en los conocimientos tradicionales de las comunidades, demostrando la existencia de una memoria biocultural representada por los saberes locales (Toledo 2009), la supuesta dicotomía campo-ciudad, y fenómenos como el abandono de la vida rural, el incremento de las labores agrícolas convencionales (basadas en agroquímicos, explotación intensiva y extensiva de los recursos naturales), así como la presión sobre los ecosistemas, la demanda de recursos para las grandes ciudades, plantea nuevos retos para los estudios etnoecológicos, que buscan seguir las vetas de interacción entre los sujetos, sus alimentos y su medioambiente (Toledo 1990).

4 En Cuba, la relación entre el campo y la ciudad se ha caracterizado por ser estrecha y comprometida. Esto, gracias a la unidad nacional construída a partir de las conquistas sociales y políticas del movimiento revolucionario de 1950. Sin embargo, como nación, Cuba no cuenta con recursos energéticos propios y el acceso a los mismos se ve dificultado por su situación geográfica. Por lo tanto, para comprender la relación que establecen las personas con sus recursos naturales en el contexto cubano, se requiere considerar, no sólo los factores geográficos y sociales ya mencionados, sino también es imprescindible incorporar al análisis factores económicos, políticos, tanto a nivel nacional como internacional. Por lo que es necesario un abordaje que por una parte estudie "las concepciones, percepciones y conocimientos sobre la naturaleza que permiten a las sociedades naturales producir y reproducir las condiciones materiales y espirituales de su existencia social a través de un manejo adecuado de sus recursos naturales o ecosistemas" (Toledo 1990), pero que además integre al análisis los factores externos, de tipo económico y político. Es decir, en un mundo global, los cambios sociopolíticos, en sus diferentes escalas, tienen efectos que trastocan la vida cuotidiana, desde los modos de producción hasta el gusto por nuevos alimentos y con ello cambios en las tradiciones culinarias. Desde este enfoque, el caso cubano es particularmente de gran interés para el análisis, ya que durante las últimas décadas han acontecido cambios drásticos en los sistemas de producción de alimentos que han llevado a incorporar de manera urgente una mayor variedad de cultivos, lo que llevó a un proceso de aceptación y adaptación de los mismos en el gusto popular en lapsos de tiempo muy cortos como explicaremos más adelante.

5 En esta investigación, se ha tomado, como eje de análisis, el consumo de alimentos que popularmente se denominan "viandas". En esta clasificación encontramos tubérculos, raíces y rizomas como ; yuca (Manihot esculenta), ñame (Dioscorea spp.), boniato (Ipomoea batata), papa (Solanum tuberosum), malanga (Colocasia esculenta y Xanthosoma sp.). De manera aparentemente arbitraria se incluye el plátano (Musa sapientium) que es una fruta y una hortaliza como la calabaza (Cucurbita maxima). El estudio de la producción y consumo de viandas resulta de particular relevancia por ser elementos importantes dentro la gastronomía cubana y que, a excepción de la papa, son los únicos cultivos en los cuales el país es autosuficiente. Estos alimentos se encuentran históricamente arraigados 
en la dieta del Cubano, y su producción implica la aplicación de la experiencia y conocimientos agrícolas trasmitidos generación tras generación. Sin embargo, durante las últimas décadas, el sistema político, económico y social de Cuba, ha sido impactado repetidas veces por fuerzas políticas externas y cambios en el orden político internacional que han logrado modificar las formas tradicionales de producción, al mismo tiempo que se han incorporado nuevos cultivos.

\section{Antecedentes del consumo de viandas}

6 La presencia de raíces y tubérculos en la dieta del cubano, es parte de su pasado indígena. Tubérculos como la yuca y el boniato fueron algunos de los alimentos de los habitantes originarios que se sumaron a la dieta de los Españoles que ocuparon la isla hace cinco siglos (Núñez \& González 1999). Si bien la población indígena nativa fue desapareciendo durante la ocupación española, la mano de obra de esclavos negros traídos de África y la migración proveniente de las Islas Canarias influenciaron de forma importante a la gastronomía de la isla. Estos flujos migratorios trajeron consigo nuevos hábitos alimenticios, desde el consumo de carne de cerdo y res, hasta el consumo de plátano, arroz, frijol, trigo y papa, productos que no eran propios de la isla, más sin embargo, ahora son parte fundamental de la dieta de la población cubana.

7 Aunque se sabe que el maíz y la yuca ya existían desde antes de la colonización española, no hay mucha precisión histórica respecto a cómo se fueron integrando otras variedades de vianda como el ñame (Dioscorea), la malanga (Colocasia y Xanthosoma) o el boniato ( Ipomoea), el cual tiene tan solo alrededor de 200 años de haber llegado a la Isla. Respecto al cultivo del plátano (Musa), Alejandro García en su ensayo "Santo, seña y ruta histórica del plátano hasta Cuba" (2001) afirma que de la costa occidental de África y después de las Islas Canarias partieron las primeras cepas de plátano hacia Cuba a principios del XVI. Según la literatura, desde tiempos de la colonia, en islas como Puerto Rico, el plátano, en un principio, era fundamentalmente un alimento para esclavos negros, e incluso para algunos blancos pobres (Díaz 1981). En Cuba, se considera que platillos tradicionales como el fufú tienen su origen en costumbres culinarias africanas (Ortiz 1924), incluso el platillo en sí mismo es un vestigio del sincretismo cultural de las diversas poblaciones de negros procedentes de distintas comarcas costeñas africanas, desde Senegal, Guinea, Congo y Angola en el Atlántico, hasta Mozambique en la contracosta del continente africano (Ortiz 1983).

\section{La agricultura intensiva en Cuba}

Debemos tomar en cuenta que en Cuba, tanto el modelo como la práctica agrícola, son el resultado de dos circunstancias particulares ; por una parte, la herencia colonial y por otra la llegada del capital norteamericano, ambas terminaron en un modelo de explotación capitalista de la tierra (Machín et al. 2011). Una vez triunfada la Revolución, el 17 de mayo de 1959, se firmó la primera Ley de Reforma Agraria, y una segunda el 3 de octubre de 1963, ambas buscarían liquidar los latifundios para redistribuir la tierra a miles de agricultores que la trabajaban sin ser dueños. Estas reformas recuperaron también miles de caballerías para el patrimonio nacional. Durante los primeros 15 años posteriores a la revolución, se había duplicado la superficie cultivada y los índices productivos se mantenían en aumento (ídem). 
9 En 1972, Cuba ingresa al Consejo de Ayuda Mutua Económica (CAME), con ello se formalizó su participación en la llamada "División internacional socialista del trabajo". Con ello, la estrategia de desarrollo del país comienza a ser concebida como parte de la estrategia global de la economía socialista mundial (Miranda 2003). Mientras los acuerdos económicos con el bloque socialista aseguraban la comercialización (a precio favorable) del $70 \%$ de la producción, otro $15 \%$ se comercializaba con los demás países del bloque socialista y el $15 \%$ restante se comercializaba a otros países a precios de mercado internacional. Los ingresos obtenidos por las exportaciones se utilizaban para comprar químicos, combustible y alimentos para la población (Machín et al. 2011). Los compromisos comerciales de Cuba con el bloque socialista implicaron una tecnificación y especialización de la agricultura sin precedentes. A finales de la década de 1980, se importaba el $95 \%$ de los insumos agrícolas y el $57 \%$ de los alimentos que se consumían al interior de la isla (Wright 2009).

\section{El colapso del bloque socialista y su efecto en la seguridad alimentaria}

La aplicación del modelo industrial de la revolución verde en Cuba se había facilitado gracias a la fuerte relación con los países socialistas del Este de Europa y en particular con la Unión Soviética. Para cubrir la demanda comercial con estos países, el 50 \% de la tierra cultivable de la isla, se destinó a responder a la demanda externa de básicamente tres productos ; azúcar, tabaco y cítricos (Funes-Monzote 2001). Destinar una gran superficie de tierra para monocultivos, en un sistema de producción altamente industrializado, tendría consecuencias ambientales, sociales y económicas severas. Después de 25 años de producción agrícola mecanizada y a base de agroquímicos, la población rural pasó de un $56 \%$ a un $28 \%$, mientras que el sistema productivo para sostenerse requería de un uso excesivo de insumos y energía fósil (idem).

11 A fines de 1989 y 1990, la desaparición del bloque socialista marcó el fin de las relaciones comerciales con los países socialistas. Como consecuencia, entre 1990 y 1993, el PIB de Cuba tuvo una contracción acumulada del 34.8\%. Todos los sectores de la economía sufrieron los rigores de la crisis (Miranda 2003). Ante tales circunstancias, la capacidad de la isla para autoabastecerse de alimentos, era muy reducida y dependía de insumos externos que ya no era posible seguir importando. Uno de los principales problemas para las importaciones, era el bloqueo comercial estadounidense, el cual representaba un importante obstáculo para abastecerse de los insumos agrícolas y energéticos por parte de otros países.

12 Es así como el devenir de los conflictos políticos internacionales llegaron a la mesa. Es decir, el arroz, frijol, trigo e incluso el garbanzo (integrado en la época postrevolucionaria por sus altos niveles de proteína), alimentos básicos en la dieta del -

Cubano, en gran medida eran importados, o se producían de manera insuficiente dentro de la isla (Wright 2009), y casi desaparecieron.

13 En 1991, como respuesta a la crisis económica y alimentaria, inicia lo que se conocería como el "Período especial en tiempos de paz", caracterizado por diversas reformas políticas de austeridad y por un estilo de economía de tiempos de guerra (Machín et al. 2011). Entonces, fue prioritario combatir el desabasto de alimentos y fortalecer las políticas sociales. Gracias a ello, durante los años más difíciles del período especial, se 
logró racionar de manera equitativa los escasos alimentos disponibles, a la par de que se continuaron reforzando los programas sociales para combatir la mortalidad infantil y la desnutrición (Funes-Monzote 2001) ${ }^{3}$.

Mientras se fortalecía la producción interna de granos y semillas, se enfatizó la reproducción de alimentos adaptados a las condiciones climáticas y geográficas de la isla como es el caso de la mayoría de las viandas. Sin embargo, pasar de una agricultura industrializada de altos insumos externos a una agricultura de bajos insumos, no fue tarea fácil. Después de décadas de uso intensivo de agroquímicos, el deterioro de la superficie agrícola llego a ser del $76.8 \%$ del suelo cultivable, el cual oscilaba entre poco a muy poco productivo (Instituto de Suelos 2001). La degradación de la mayor parte de la superficie agrícola se hizo evidente ante la drástica disminución de fertilizantes. Se calcula que después de 1991 cuando los insecticidas dejaron de estar disponibles, las plagas así como sus daños se incrementaron significativamente (Maza et al. 2000).

\section{Producción de viandas y subsistencia alimentaria}

En general las viandas son productos alimenticios bien adaptados a las condiciones físicas y climáticas de la región (excepto en el caso de Solanum tuberosum), además que son productos que se producen en buena cantidad. De manera particular, durante el período especial, las viandas fueron un alimento clave por su capacidad de suministrar altos niveles de carbohídratos para el organismo y, en el caso del plátano, de potasio, minerales y vitaminas. Por sus características y para asegurar el abastecimiento de estos productos, el gobierno cubano hizo un esfuerzo por seguir importando semilla de papa (Solanum tuberosum), la cual a pesar de no ser nativa de la isla es un producto de alto rendimiento, que complementa de manera importante el abastecimiento de viandas a lo largo del año. A diferencia de otras viandas, la producción de papa implica la mayor inversión en insumos.

A pesar de que las viandas son cultivos de fácil reproducción, sin la disponibilidad de agroquímicos, se mostraron altamente vulnerables al tratar de ser reproducidas como monocultivos en tierras deterioradas (Funes-Monzonte 2001). Al respecto, uno de los cultivos que sufrió mayores daños, fueron las variedades de plátano-vianda (Musa paradisiaca) y plátano-fruta ( $M$. paradisiaca var. nana) más consumidas. Estas casi desaparecieron por la afectación de la sigatoka amarilla ${ }^{4}$, la cual una vez introducida al sistema de monocultivo es imposible de controlar, ya que en los cultivos de plátano, la proximidad entre especies y su siembra extensiva, solo hacían posible el manejo de plagas a partir de la fumigación desde aviones. Lo cual no era posible en aquellas condiciones de limitación de insumos. En la búsqueda de alternativas, se introdujeron al país diversas variedades de plátano, de las cuales algunas resultaron resistentes a la sigatoka y útiles para cocinarse como vianda. La introducción de nuevas variedades de plátano fue una rápida solución, estas variedades de clones resistentes a la sigatoka amarilla fueron en su mayoría proveniente de la Fundación Hondureña de Investigaciones Agrícolas (González et al. 2009). Si bien al principio la variedad de plátano Musa sp. ABB no gustaba a los consumidores, la falta de opciones llevó a que poco a poco fuera ganando espacio en la cocina y el gusto de los Cubanos, como veremos más adelante.

Durante el período especial, el consumo de viandas fue clave y se acompañó de otros cambios importantes dentro del sistema de producción de alimentos. La urgencia de lograr una dieta adecuada, llevó a que se estimulara la producción urbana y periurbana de 
hortalizas, frutas y ganado menor, incluso de especies que antes no eran frecuentes en la dieta popular ${ }^{5}$. Ante la demanda de alimentos, se desarrollaron y difundieron sistemas alternativos de producción, en gran parte basados en los sistemas de producción de pequeños agricultores de bajos insumos, y que poco o nada fueron afectados por la falta de importaciones de químicos y combustible (Machín et al. 2011, Funes-Monzonte 2001).

El paso hacia sistemas agropecuarios de bajos insumos, implicó también cambios drásticos en la capacidad de producción de carne. Tan sólo de 1990 a 1993 la falta de insumos agroquímicos para la producción de forraje, implicó la perdida de un $63 \%$ de la masa ganadera (ONE 1997). Ante la poca disponibilidad de insumos agrícolas, el sistema de producción ganadera a gran escala dejó de ser funcional y se optó por descentralizar la producción y distribución de carne y leche ${ }^{6}$. Mientras se recupera la masa de ganado vacuno, se ha intensificado la cría y consumo de ganado menor, el cual es de rápido crecimiento, demanda poco alimento y es de fácil reproducción incluso en espacios urbanos.

\section{Estudio de caso}

Tomando como referente a los pobladores de Güira de Melena, esta investigación busca : 1) conocer cuales son las viandas preferidas, como las identifican y preparan de forma cuotidiana y 2) describir como el gusto por nuevas variedades de vianda ha sido una forma de adaptar el paladar a las transformaciones de los sistemas productivos durante el período especial. La recolección de datos se efectuó durante el mes de noviembre de 2011; se realizaron siete entrevistas a profundidad a hombres y mujeres que radican en el poblado de Güira de Melena. Así mismo se entrevistaron académicos y funcionarios miembros de la Asociación Nacional de Agricultores Pequeños (ANAP), a un Chef y al responsable de la comercialización de los productos en el agromercado de Güira de Melena. Se llevaron a cabo también visitas domiciliarias a los entrevistados y recorridos etnográficos por las calles de la ciudad y fincas tanto agroecológicas como convencionales. 


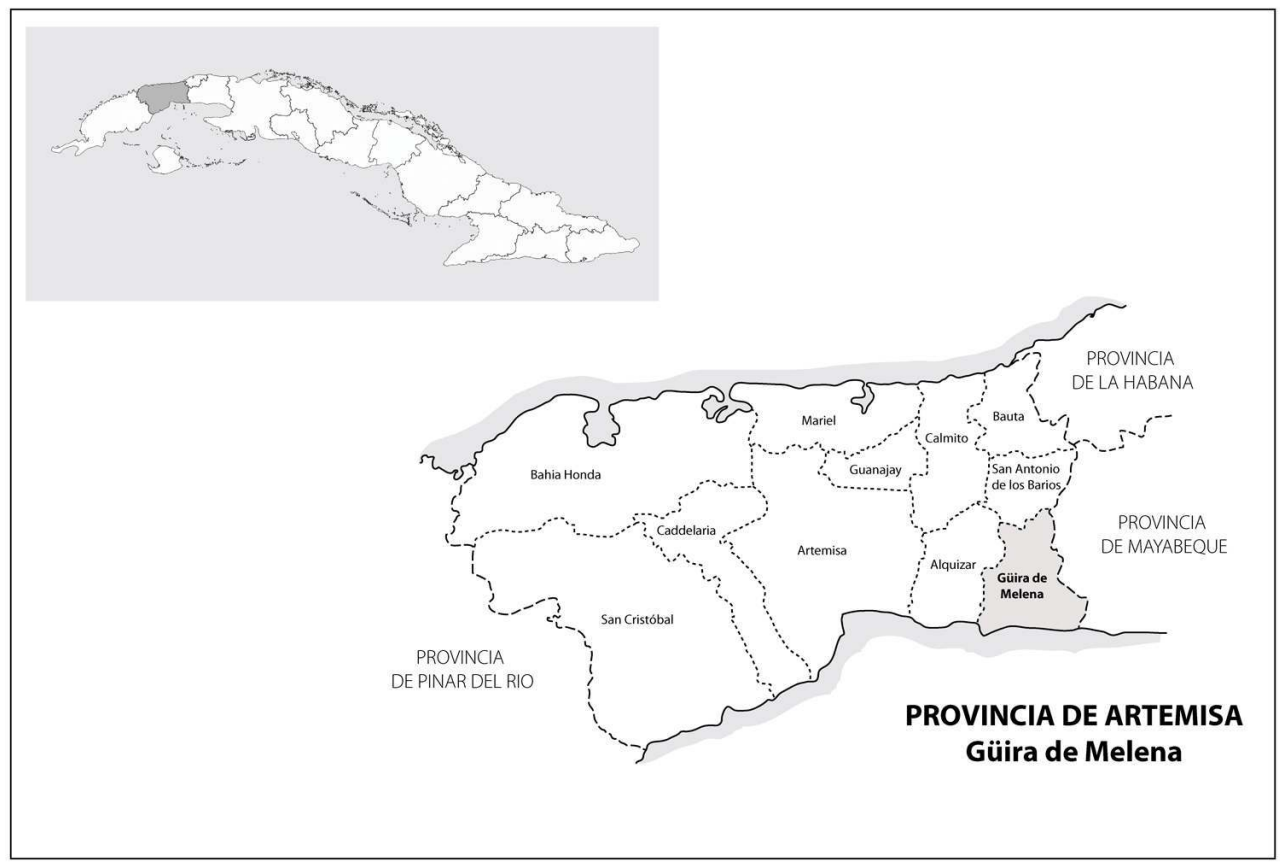

FUENTE : WWW.ECURED.CU

Güira de Melena cuenta con una superficie de $177 \mathrm{~km}^{2}$ y una población de 39,990 habitantes, el $26 \%$ radica en zonas rurales (ONE 2010). La principal actividad económica es la agricultura. Los suelos fértiles de arcilla roja, característicos de Güira de Melena, son en particular propicios para la producción de tubérculos y raíces. Gracias a ello, la superficie sembrada en 2010 (93 870.216 ha), el $43.88 \%$ se destinó al cultivo de raíces y tubérculos, el $16.77 \%$, para siembra de plátano y un $22.69 \%$ para hortalizas (ídem).

\section{Las viandas y sus características}

De acuerdo con los entrevistados, se considera 'vianda' a aquellas variedades de malanga, boniato, papa, ñame, yuca, calabaza y plátano que se utilizan para acompañar principalmente el arroz y frijol. Este grupo de alimentos se compone de un primer grupo de raíces, rizomas y tubérculos comestibles, el plátano que es una fruta y la calabaza que es un fruto de hortaliza. Estos últimos son considerados vianda, siempre y cuando se coman "cocidos", "fritos" o ambas cosas.

Por tanto, el plátano dulce (Musa nana) que se come maduro y crudo, no se considera vianda, y se le suele nombrar "plátano fruta" para diferenciarlo del "plátano vianda" ( Musa paradisiaca y Musa sp. ABB) que se cocina completamente verde. Sin embargo, algunos entrevistados señalaron que el plátano dulce o plátano fruta en trozos, es utilizado con frecuencia para acompañar el congrí o arroz moro. 
Foto 1. Viandas disponibles en casa de una entrevistada

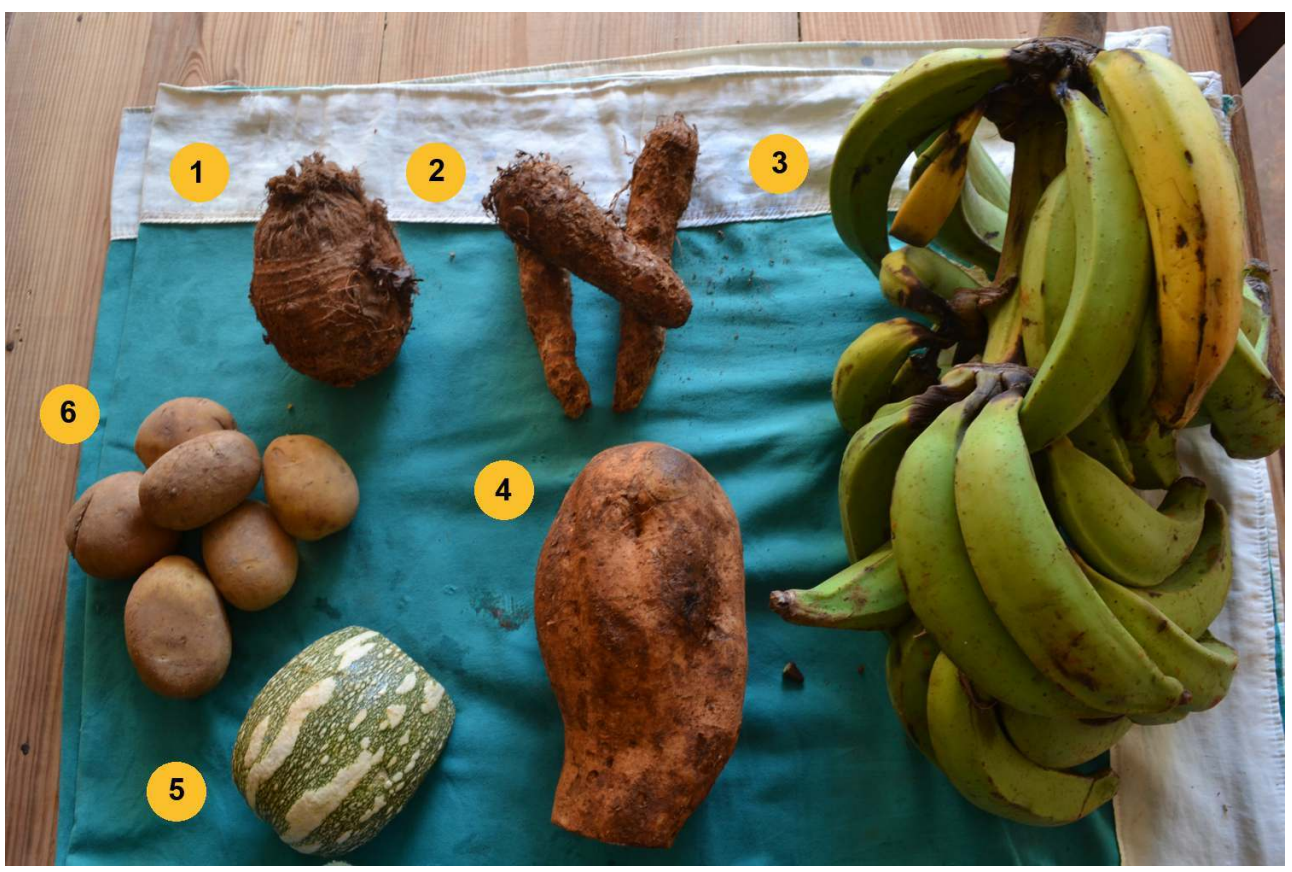

1. Ñame (XANTHOSOMA SAgITtIFoliUM (L.) SCHOTt) ; 2. Malanga Isleña (DIOSCOREA ALATA L.) ; 3. Plátano burro (MUSA SP. ABB) ; 4. Boniato (IPOMOEA BATATAS (L.) LAM.) ; 5. Calabaza (CUCURBITA MAXIMA DUCHESNE) ; 6. Papa (SOLANUM TUBEROSUM SW.)

Cabe señalar que la integración de la calabaza (Cucurbita) como una vianda, se encuentra en debate, ya que entre los investigadores entrevistados, uno definitivamente la consideró sólo como una hortaliza ${ }^{7}$, dejando la clasificación de viandas para las raíces, tubérculos y rizomas. Sin embargo, desde un punto de vista emic, la calabaza esta clasificada como una vianda por parte de los habitantes de Güira de Melena que fueron preguntados. Esto se debe a que en ciertos platillos el modo de preparación de la calabaza, sigue los mismos patrones de las demás viandas ${ }^{8}$. Esto nos indica que independientemente si es raíz, tubérculo, rizoma, fruto $u$ hortaliza, las viandas en su conjunto :

1. Se consideran un complemento importante del arroz y frijol.

2. No se pueden comer crudos (el plátano-vianda es verde; cuando se come crudo, es porque está maduro y entonces es considerado fruta).

3. Para acompañar la comida, se deben cocer, freír o ambos.

4. Se pueden preparar tanto salados como dulces (según el gusto de la persona).

Es decir, más allá de las cualidades organolépticas, el punto en común de los distintos productos que se consideran viandas, tiene que ver con la forma en que son preparados y consumidos. Otra propiedad es que la mayoría de las viandas son alimentos que pueden tornarse fácilmente dulces o salados, incluso ambas cosas, esto a excepción del plátano, del boniato dulce (Ipomoea batata), además de algunos tipos de ñame que son picantes y se utilizan principalmente como alimento para animales. 


\section{Variedades, usos y costumbres en el consumo de viandas}

Para la población cubana el tener gusto por las distintas variedades de viandas es importante ya que si bien la mayoría se encuentra a la venta durante la mayor parte del año, cambios climáticos repentinos pueden afectar la disponibilidad de algunos de los productos. La yuca, por ejemplo, resiste bien a temporadas de sequía, pero un exceso de humedad afectaría de manera importante la producción. De manera opuesta, la malanga requiere de humedad para su buen desarrollo, la falta de riego o lluvia disminuiría su rendimiento. Ambos tubérculos al igual que el boniato y ñame, tienen como almacén la parcela y se deben vender frescos, ya que se dañan si se les almacena por largo tiempo o si se ponen en refrigeración. Por este motivo, la papa juega un papel importante en la seguridad alimentaria del país, ya que esta, a diferencia de las otras raíces, se produce una vez al año (en invierno), pero se le puede almacenar en congeladores para liberarse al mercado cuando sea necesario.

En la Tabla 1 se muestra una sistematización del uso y formas de preparación de las distintas viandas que los entrevistados señalaron como las que común mente utilizan. Al respecto, podemos decir que el consumo de viandas, no sólo se enfoca a usos culinarios, sino que también se reconocen algunas propiedades medicinales, así mismo utilizadas también para la alimentación de mascotas en casa o cerdos de engorda. Cabe mencionar que en la literatura se pueden encontrar un mayor número de usos medicinales, e incluso esotéricos (Pérez et al. 2005; Bacallao 1997; Fernández et al. 2002).

Tabla 1. Clasificación de viandas por nombre científico y usos señalados por los entrevistados

\begin{tabular}{|c|c|c|c|c|c|}
\hline \multicolumn{2}{|c|}{$\begin{array}{l}\text { Vianda } \\
\text { Nombre común }\end{array}$} & Nombre cientifico & Usos medicinales & Usos culinarios & Otros usos \\
\hline \multirow[b]{2}{*}{ Malanga } & $\begin{array}{l}\text { Malanga isleña } \\
\text { o Ñame isleño }\end{array}$ & $\begin{array}{l}\text { Colocasia esculenta } \\
\text { (L.) Schott }\end{array}$ & Ulceras & $\begin{array}{l}\text { Frita, cocida, con mojo. Sopa, } \\
\text { guisos: potaje, caldosa. }\end{array}$ & -- \\
\hline & Malanga guaguil & $\begin{array}{l}\text { Xanthosoma sagittifolium } \\
\text { (L.) Schott }\end{array}$ & $\begin{array}{l}\text { Diarrea, intoxicación, } \\
\text { antiácido, problemas } \\
\text { gástricos, } \\
\text { Indigestión }\end{array}$ & $\begin{array}{l}\text { Frita, cocida, con mojo. Sopas, gui- } \\
\text { sos: potaje, caldosa. La hoja es } \\
\text { comestible, se usa en sopa con poca } \\
\text { frecuencia. }\end{array}$ & $\begin{array}{l}\text { Recomendado como } \\
\text { primer alimento sólido } \\
\text { para bebés y } \\
\text { enfermos }\end{array}$ \\
\hline \multicolumn{2}{|r|}{ Boniato } & $\begin{array}{l}\text { Ipomoea batatas } \\
\text { (L.) Lam. }\end{array}$ & Diabetes, & $\begin{array}{l}\text { Cocido, frito, en postre: boniatillo, } \\
\text { malarrabia guisos: ajiaco, caldosa. }\end{array}$ & $\begin{array}{l}\text { Cocido es alimento de } \\
\text { perro y cerdos }\end{array}$ \\
\hline \multicolumn{2}{|r|}{ Papa } & $\begin{array}{l}\text { Solanum tuberosum } \\
\text { Sw }\end{array}$ & --- & $\begin{array}{l}\text { Frita, cocida, con mojo, fricasé, } \\
\text { guisos: potaje, caldosa. }\end{array}$ & --- \\
\hline \multirow{3}{*}{ Plátano } & $\begin{array}{l}\text { Fruta } \\
\text { Manzano }\end{array}$ & $\begin{array}{l}\text { Musa sapientium } \\
\text { L., } \\
\text { y Musa nana }\end{array}$ & $\begin{array}{l}\text { El fruto maduro es } \\
\text { recomendado para } \\
\text { problemas en las } \\
\text { articulaciones }\end{array}$ & $\begin{array}{l}\text { Maduro, no se considera vianda, sin } \\
\text { embargo, tambien se sirve en crudo } \\
\text { para acompañar el arroz y los frijoles. }\end{array}$ & $\begin{array}{l}\text { Recomendado para } \\
\text { deportistas }\end{array}$ \\
\hline & Macho & $\begin{array}{l}\text { Musa } \\
\text { paradisiaca }\end{array}$ & --- & $\begin{array}{l}\text { Consumo en verde cocido, frito, en } \\
\text { chicharrita, tostón, con mojo, en fufú, } \\
\text { ajiaco y caldosa. }\end{array}$ & --- \\
\hline & Burro & $\begin{array}{l}\text { Musa } \\
\text { sp. ABB }\end{array}$ & $\begin{array}{l}\text { Consumido en fruta } \\
\text { ayuda a prevenir } \\
\text { calambres }\end{array}$ & $\begin{array}{l}\text { Consumo en verde cocido, frito, en } \\
\text { chicharrita, tostón Frita, cocido, } \\
\text { sancochada con mojo, en fufú, ajiaco } \\
\text { y caldosa. }\end{array}$ & --- \\
\hline \multicolumn{2}{|r|}{ Yuca } & $\begin{array}{l}\text { Manihot esculenta } \\
\text { Crantz }\end{array}$ & --- & $\begin{array}{l}\text { Frita, cocida, con mojo, ajiaco, } \\
\text { caldosa. Buñuelo }\end{array}$ & --- \\
\hline \multirow[b]{2}{*}{ Ñame } & Ñame amarillo & $\begin{array}{l}\text { Dioscorea cayenensis } \\
\text { Lam. }\end{array}$ & $\begin{array}{l}\text { Problemas } \\
\text { digestivos }\end{array}$ & $\begin{array}{l}\text { Frito, cocido, con mojo, ajiaco, } \\
\text { caldosa. }\end{array}$ & --- \\
\hline & Ñame de agua & $\begin{array}{l}\text { Dioscorea alata } \\
\text { L. }\end{array}$ & --- & $\begin{array}{l}\text { Frito, cocido, con mojo, caldosa. En } \\
\text { trozos con huevo revuelto. Su sabor } \\
\text { neutro lo hace un producto versátil } \\
\text { que puede tender a dulce o salado. }\end{array}$ & ---- \\
\hline \multicolumn{2}{|r|}{ Calabaza } & $\begin{array}{l}\text { Cucurbita maxima } \\
\text { Duchesne. }\end{array}$ & $\begin{array}{l}\text { Las semillas } \\
\text { se consumen } \\
\text { para desparasitar }\end{array}$ & $\begin{array}{l}\text { Cocida, frita, potaje, flan, ajiaco, } \\
\text { caldosa. }\end{array}$ & ---- \\
\hline
\end{tabular}

Como ya se mencionó respecto a los usos y formas de preparación de las viandas, la neutralidad del sabor de algunas de ellas permite que al prepararlas se tornen fácilmente 
dulces o saladas. Al respecto encontramos que si bien dicha elección responde al gusto personal, cuando se tienen niños pequeños en casa, se prefiere preparar las viandas dulces. En el caso de la malanga que es muy recomendada para los niños, esta se prepara con azúcar, para que sea más agradable. La malanga también es muy apreciada por sus cualidades digestivas, se recomienda como primer alimento de los bebés y como medicamento para problemas gástricos. Si bien en las entrevistas, la malanga y ñame son reconocidos por sus cualidades digestivas, dentro de la literatura se puede encontrar también que el ñame guinea (Dioscorea cayenensis Lam.) se puede utilizar como un cicatrizante, antimicótico, ayuda a mitigar los trastornos de la menopausia, aunque tambien se advierte que puede causar daños renales. Mientras el ñame de agua (Dioscorea alata L.) es recomendado como antidepresivo, antienvejecimiento, para tratamiento de la diabetes y para mejorar la memoria, sin embargo su ingesta durante el embarazo puede provocar aborto (Waizel 2009). Otros estudios realizados en Cuba señalan que el boniato ( Ipomea batatas (L.) Lam.) se utiliza como galactógeno y antiartrítico, es decir estimulante de la producción de leche materna y para aliviar los síntomas de la artritis (Bernardo \& Quintana 2004). En este mismo estudio, además de la cualidad antiparasitaria de la calabaza, se resaltan sus propiedades antiespasmódicas (idem).

El plátano (tanto vianda como fruta) es reconocido por los beneficios del potasio, y se consume para disminuir problemas en las articulaciones. En otras regiones de Cuba también se utilizan las hojas y las cáscaras del fruto para tratamientos de verrugas, y la savia se mezcla con miel para el tratamiento del asma bronquial (Roig y Mesa 1914 en Fernández et al, 2002).

29 En la bibliografía se puede encontrar que dentro de las tradiciones religiosas afrocaribeñas, el ñame es comúnmente utilizado en algunos rituales. Sin embargo, entre los entrevistados, no se manifestó ningún uso religioso para este u otro cultivo. En las provincias más occidentales de Cuba (Pinar del Río y Ciudad de La Habana), las especies de ñame Dioscorea tamoidea var. tamoidgea y Dioscorea bulbifera, además de utilizarse en la alimentación, son empleados con fines religiosos en las fiestas ceremoniales de la religión yoruba, donde se les da de comer a los orishas ofreciéndoles determinados platos que se colocan al pie de la deidad (Pérez et al. 2005). En este sentido ritual, también encontramos que el plátano burro (Musa sp. ABB) y el plátano macho (Musa paradisiaca), junto con otras variedades de frutas, se suelen colocar como ofrenda para rituales propios del vudú (Galván 2008).

30 Al preguntar sobre las distintas formas de preparar las viandas, notamos que el conocimiento de las distintas variedades y recetas, está influenciada por la movilidad regional que han tenido los entrevistados. Es decir, quiénes eran originarios de Güira de Melena mencionaron una menor variedad de viandas en sus recetas, a diferencia de quienes provenían de otras regiones. Estos últimos, mostraron conocimiento de una mayor cantidad de especies y usos de viandas. Un ejemplo de ello es el ñame, vianda que fue mencionada pocas veces por los habitantes de Güira, sin embargo, para uno de los entrevistados que provenía del oriente de Cuba, el consumo del ñame era común en su región de origen. Ese hombre hizó mención a distintas variedades de ñame: "ñame de agua" (Dioscorea alata L.) : en Güira se conoce como "ñame montón" y no se consume con frecuencia; en cambio ese mismo hombre señaló que en el oriente de Cuba, era muy apreciado para el consumo humano el "ñame de guinea" (Dioscorea rotundata) que se conoce poco en Güira, es picante y se siembra entre y el "ñame chopo" (Xanthosoma sagittifolium (L.) Schott) que, en Oriente, se utiliza también para alimentar cerdos y es 
poco apreciado para consumo humano, mientras en Güira de Melena se le conoce como "ñame guaguil" y es de uso común.

31 Por tanto, el tener mayor conocimiento sobre variedades de viandas, así como formas de prepararlas, se encontró asociado con la migración de personas de una región a otra. La movilidad regional, resultó una variante relacionada con una mayor riqueza en recetas, usos y nombres de las especies locales y de otras regiones.

\section{Consumo de viandas y tradiciones populares}

Los entrevistados enfatizaron que las viandas son, en principio, "un complemento" del arroz con frijoles, considerado como la base de su alimentación. Uno dellos mencionó "sin arroz y frijol, no hay comida". Por tanto las viandas al igual que la carne, son una forma de acompañar el típico congrí. A decir de otro, las viandas "te cambian el sabor de la comida, la hacen más gustosa... te llenan". Por lo tanto, las viandas representan una amplia posibilidad de complementar un platillo básico, pero también son una opción para sustituir el consumo de carne cuando esta no está disponible o económicamente no es posible incorporarla al menú. A partir del período especial, la carne de res por lo general no se comercializa al público en general, debido a la escasez de ganado y por su alto costo, de manera que la carne de cerdo o pollo son las que principalmente se pueden conseguir a la venta. Sin embargo para quienes tienen un bajo ingreso económico el precio destos es poco accesible.

Los platillos a base de viandas, se han venido modificando con el tiempo, un ejemplo de ello es la tradición de "la caldosa". Según la tradición, cada 28 de septiembre en toda la isla, se conmemora la conformación de los Comités de Defensa de la Revolución (CDR), los cuales representan la base de la organización y participación ciudadana en Cuba. La forma de festejar cada aniversario consiste en la preparación colectiva de un platillo peculiar "la caldosa". Este es una variante del ajiaco cubano, con la diferencia de que la caldosa es un platillo vinculado a la conmemoración de eventos asociados al triunfo de la Revolución. Este platillo se cocina en grandes cantidades y contiene básicamente carne de pollo, diversos tipos de viandas y jugo de tomate. Al ser parte de un festejo popular, en los barrios cubanos, la preparación y consumo de la caldosa se realiza de manera colectiva y comúnmente se acompaña con ron. Aunque no se sabe con precisión cuando se inició esta tradición, se cree que fue entre 1960 y 1970 . Poco a poco esta forma de celebración se fue adoptando en cada una de las provincias de Cuba. La caldosa ha sido tan bien aceptada que incluso se ha extendido como platillo para otro tipo de festejos considerándose actualmente como parte de la gastronomía popular cubana.

Como ya se ha mencionado anteriormente, durante el período especial, el consumo de viandas fué de extrema importancia. Según testimonios, ante el cierre de importaciones y el deficit interno en la producción de arroz y frijol, las familias de grandes ciudades como la Habana podían comer por varios días solo uno o dos tipos de vianda, muchas veces con dificultad para conseguirlas y sin posibilidad de escoger la de su preferencia. Ante el deficit de producción de carne, algunas personas llegaban a engordar cerdos en el interior de sus casas, en sus patios, o de forma colectiva algunos vecinos se organizaban para engordar animales en sus jardines o espacios disponibles. 
Foto 2. Comida típica cubana

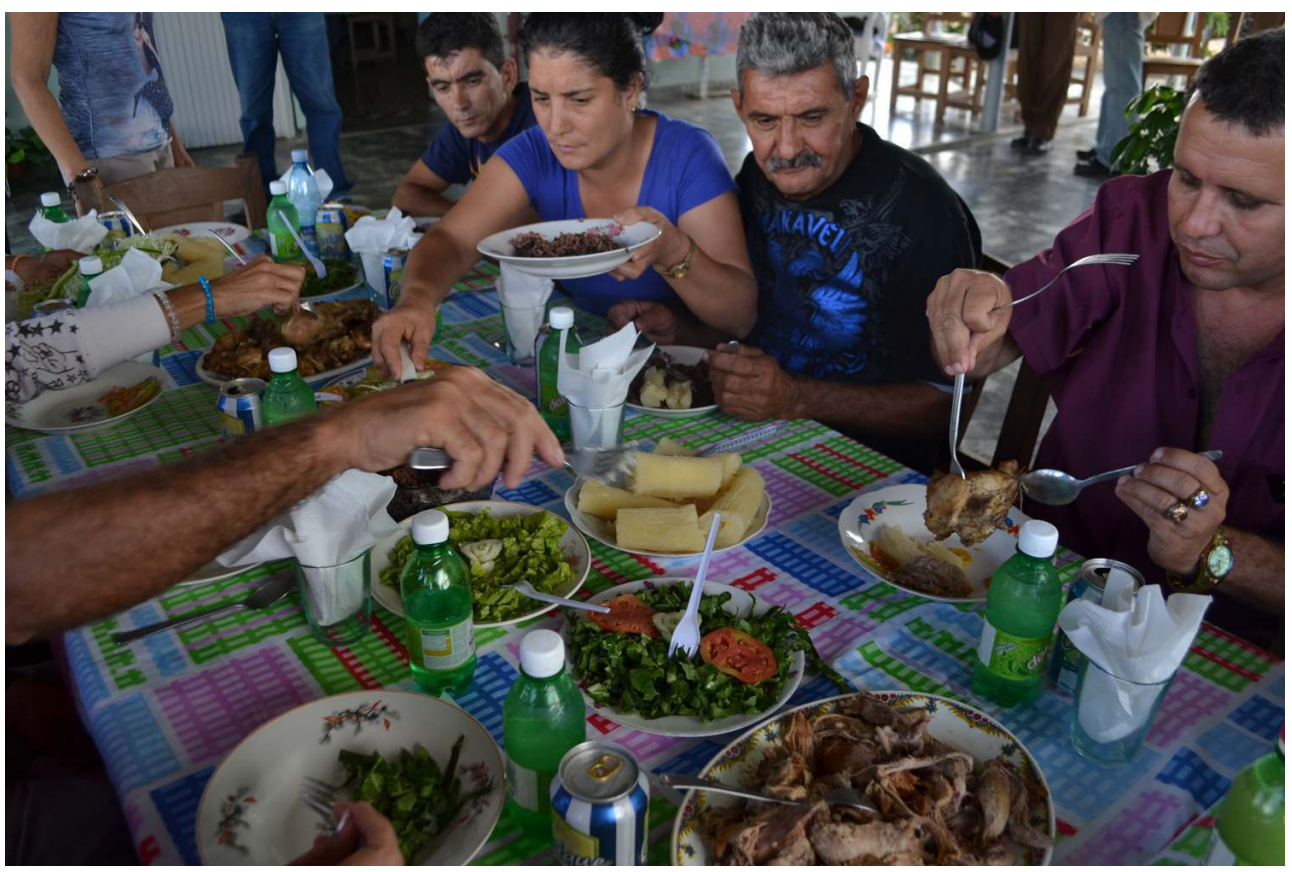

En el caso de ciudades menos pobladas como Güira de Melena, las familias cercanas a zonas agrícolas tenían una mayor posibilidad de producir parte de sus alimentos, desde viandas hasta hortalizas y frutas como la guayaba (Psidium guajava), fruta bomba (Carica papaya), naranja (Citrus sinensis), incluso criar ganado menor (ovino, porcino y aves de corral) para el autoconsumo. Durante la escasez de alimentos, la producción de autoconsumo se realizaba en los patios de las casas o, en algunos casos, en terrenos, logrando con ello una mejor alimentación respecto a las familias de las grandes ciudades.

Foto 3. Comida típica cubana

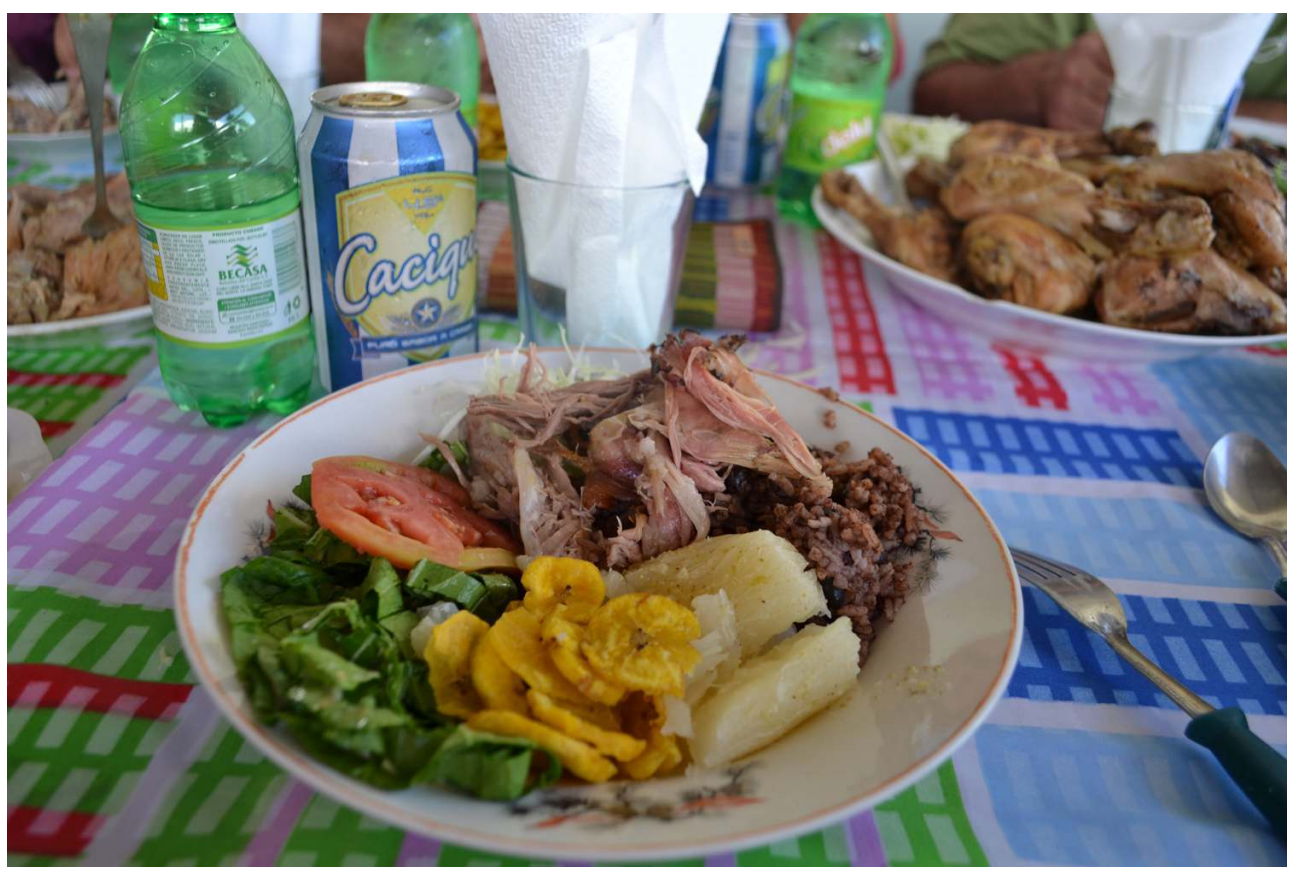

Congrí con carne de cerdo, yuca cocida, chicharritas de plátano, ensalada con mojito 
La necesidad de integrar una dieta balanceada llevó la incorporación de una mayor cantidad de hortalizas, lo que representó un cambio importante en la dieta de las familias cubanas. Esto gracias a los programas gubernamentales de capacitación para el establecimiento de huertos familiares, en zonas urbanas y periurbanas y a las insistentes campañas en medios de comunicación para incorporar nuevos alimentos a la dieta familiar. Hasta antes del período especial, el consumo de zanahoria (Daucus carota) y acelga (Beta vulgaris var. cicla), rábano (Raphanus sativus), espinaca (Spinacia oleracea) entre otros, era escaso. Sin embargo actualmente son alimentos comunes para los Cubanos, principalmente los que habitan en zonas urbanas. Al decir de uno de los entrevistados, "Los Cubanos hemos ganado mucho en la cultura del consumo de las hortalizas... y se lo agradecemos al período especial".

Fotos 4 y 5 . Casas con vástagos de plátano burro

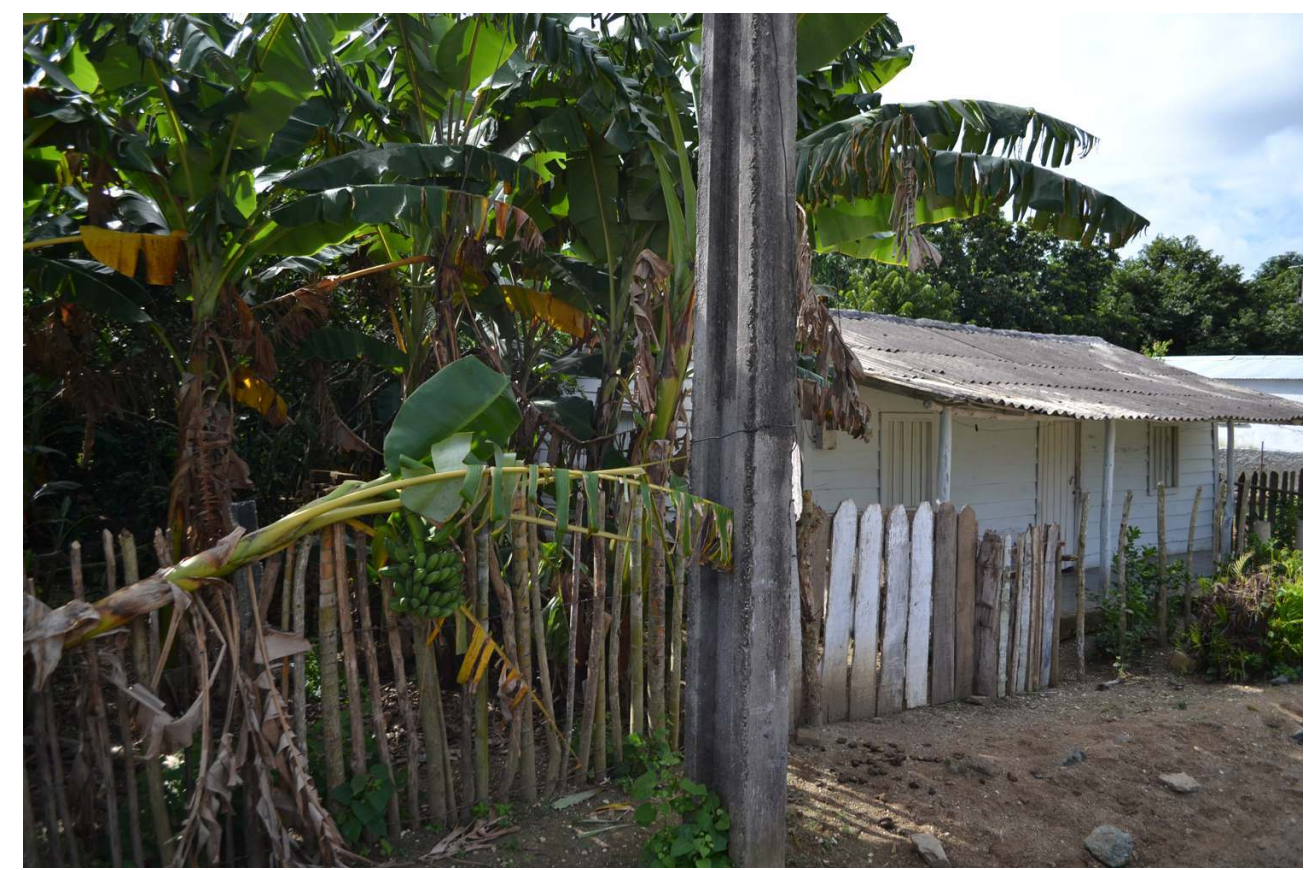




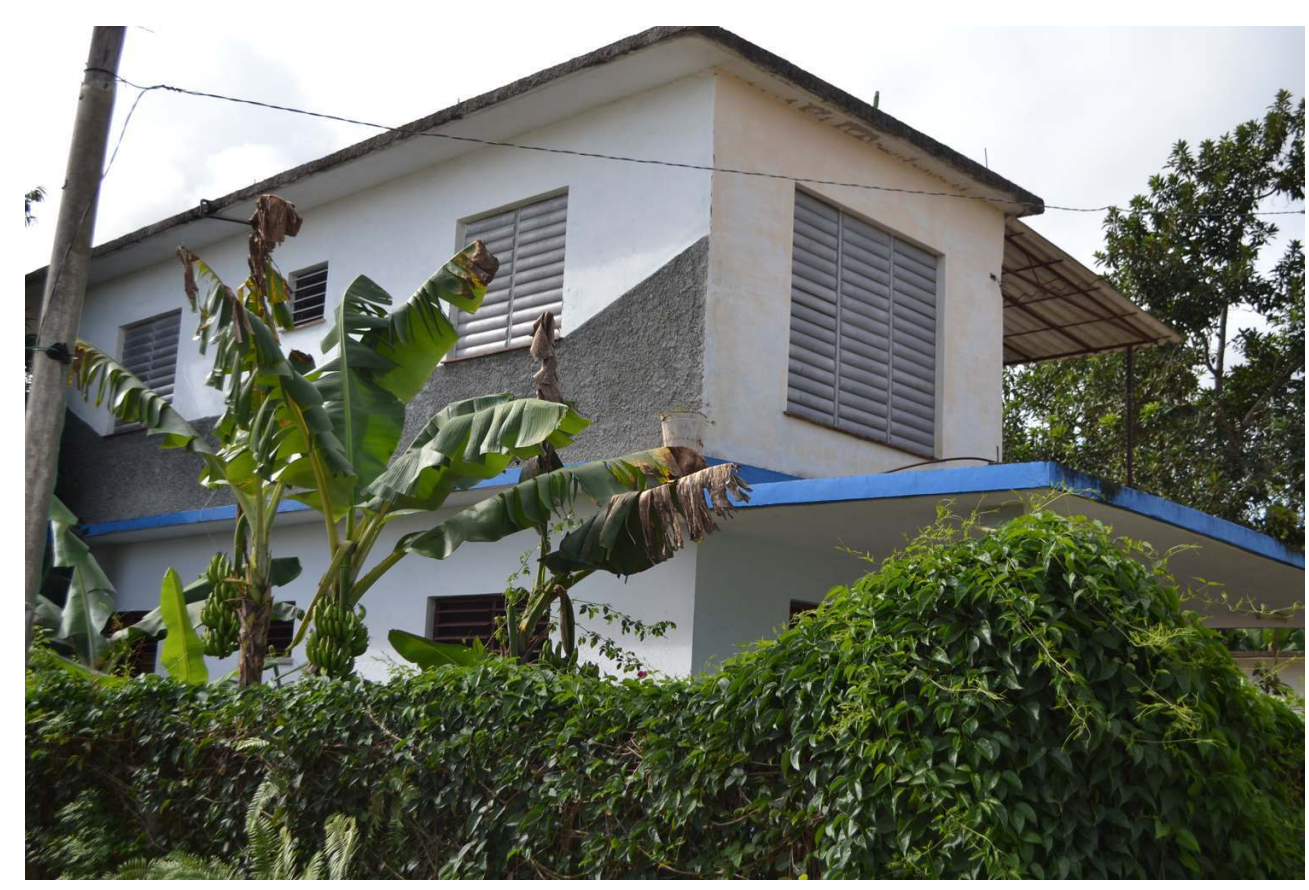

\section{Adaptación a nuevos sabores}

La escasez de productos para el control de plagas, llevó a que las variedades de plátano vianda común Musa AAB y AAA, estuvieran al borde de la desaparición (González et al. 2009). Después de experimentar con distintas variedades del género Musa, se encontró que el grupo genómico $\mathrm{ABB}$ era resistente a la sigatoka amarilla, principal plaga de los cultivos de plátano. Entre estos clones la variedad Musa sp. ABB demostró ser útil como vianda y aceptable como fruta.

En un principio, las propiedades organolépticas de esta variedad no eran del gusto popular, ya que su sabor era menos dulce que las variedades de plátano acostumbradas. Sin embargo, estas ya no estaban disponibles y por ser la única variedad en el mercado, Musa sp. ABB se popularizó por ser de doble propósito. Actualmente su aceptación es tal que se le puede observar en los jardines de las casas dentro de la ciudad y en las zonas rurales y se encuentra a la venta en cualquier establecimiento.

A más de una década y media de su introducción al mercado, la variedad Musa sp. ABB ya cuenta con un nombre popular, actualmente se le reconoce como "plátano burro". Con frecuencia es utilizado en la preparación de platillos tradicionales como el fufú y para acompañar el arroz o el congrí. Incluso algunos entrevistados señalaron que era una de sus viandas preferidas, no sólo por su sabor, sino también porque a diferencia de variedades de plátano vianda tradicionales como el plátano macho (Musa paradisiaca), al cocinarse el plátano burro se ablanda más rápidamente. Al igual que la mayoría de las viandas (a excepción de la papa), el plátano burro se puede cosechar a lo largo del año.

Como podemos ver en la Tabla 2, para un $42 \%$ de nuestros entrevistados, el plátano burro es una de las viandas preferidas para acompañar el arroz y el congrí. 
Tabla 2. Viandas que se consumen con frecuencia y las menos preferidas

\begin{tabular}{|c|c|c|c|c|c|}
\hline \multirow{2}{*}{\multicolumn{2}{|c|}{ Viandas }} & \multicolumn{3}{|c|}{ Preferencia } & \multirow[t]{2}{*}{ Observaciones } \\
\hline & & Favorito & Agrada & No gusta & \\
\hline \multicolumn{2}{|c|}{$\begin{array}{c}\text { Malanga } \\
\text { Colocasia esculenta }\end{array}$} & $28 \%$ & $58 \%$ & $14 \%$ & $\begin{array}{l}\text { Se puede conseguir la mayor } \\
\text { parte del año, pero su precio es } \\
\text { elevado. }\end{array}$ \\
\hline \multicolumn{2}{|c|}{$\begin{array}{c}\text { Boniato } \\
\text { Ipomoea batata }\end{array}$} & -- & $100 \%$ & - & $\begin{array}{l}\text { Es el producto con menor precio } \\
\text { y mayor disponibilidad durante } \\
\text { todo el año. }\end{array}$ \\
\hline $\begin{array}{c}\text { Papa } \\
\text { Solanum tuberosum }\end{array}$ & & $42 \%$ & $44 \%$ & $14 \%$ & $\begin{array}{l}\text { Hay temporadas en que esca- } \\
\text { sea en el mercado, suele tener } \\
\text { precios elevados. }\end{array}$ \\
\hline \multirow{2}{*}{ Plátano } & $\begin{array}{c}\text { Burro } \\
\text { Musa sp. ABB }\end{array}$ & $42 \%$ & $44 \%$ & $14 \%$ & $\begin{array}{l}\text { Se prefiere como vianda. Poco } \\
\text { se consume como fruta }\end{array}$ \\
\hline & $\begin{array}{c}\text { Macho } \\
\text { Musa paradisiaca }\end{array}$ & & & & No se mencionó su consumo. \\
\hline $\begin{array}{c}\text { Yuca } \\
\text { Manihot esculenta }\end{array}$ & & $28 \%$ & $82 \%$ & -- & $\begin{array}{l}\text { Gusta mucho, pero se mencionó } \\
\text { que en su cocción se gasta } \\
\text { mucho gas. }\end{array}$ \\
\hline $\begin{array}{c}\text { Ñame } \\
\text { Dioscorea esculenta }\end{array}$ & & $14 \%$ & $86 \%$ & & $\begin{array}{l}\text { Es la vianda que se consume } \\
\text { con menos frecuencia }\end{array}$ \\
\hline $\begin{array}{c}\text { Calabaza } \\
\text { Cucurbita moschata }\end{array}$ & & $14 \%$ & $86 \%$ & & $\begin{array}{l}\text { Se prefiere principalmente como } \\
\text { postre. }\end{array}$ \\
\hline
\end{tabular}

\section{Transformaciones agroecológicas para la producción de viandas}

41 Después de terminadas las relaciones con el bloque socialista y la subsecuente crisis de alimentos durante el período especial, la reducción drástica de insumos agrícolas, llevó a una reconfiguración de los sistemas productivos a escala nacional. Si bien el Municipio de Güira de Melena, previo al período especial, se distinguía por ser uno de los territorios de mayor productividad gracias a sus sistemas agrícolas altamente mecanizados y el uso intensivo de insumos agrícolas, actualmente se está recuperando la fertilidad natural del suelo (deteriorado por agroquímicos) a partir de una serie de prácticas agroecológicas implementadas a escala nacional como son : el uso de abonos orgánicos, uso de biofertilizantes, control biológico de plagas, siembra de variedades resistentes y cultivos tradicionales, uso de tracción animal, rescate de variedades tradicionales de animales, diversificación de fincas y sistemas productivos (Machín et al. 2011).

El rescate de la agricultura campesina se vió acompañado de asesoría técnica y de una serie de cambios políticos que hacían mucho más atractiva la actividad agropecuaria. A más de dos décadas de cambios estructurales en la agricultura cubana, en Güira de Melena, la Cooperativa de Créditos y Servicios Fortalecida (CCSF) $1^{\text {ro }}$ de Mayo cuenta con un centro agroecológico en donde se pone en práctica y se enseña a otros productores diversas técnicas como la producción diversificada de cultivos, manejo integral de plagas, la producción de insumos agrícolas como humus de lombriz y repelentes de insectos. La CCSF $1^{\text {ro }}$ de Mayo no sólo es responsable de producir alimentos para el mercado nacional, sino también, lleva a cabo una producción diversificada enfocada especialmente para el consumo de sus miembros y para el comercio local. Esto como parte de la estrategia nacional de diversificación y descentralización de la producción de alimentos. 
Foto 6. Curso de capitación en el huerto demostrativo de la CCFS $1^{\circ}$ de Mayo

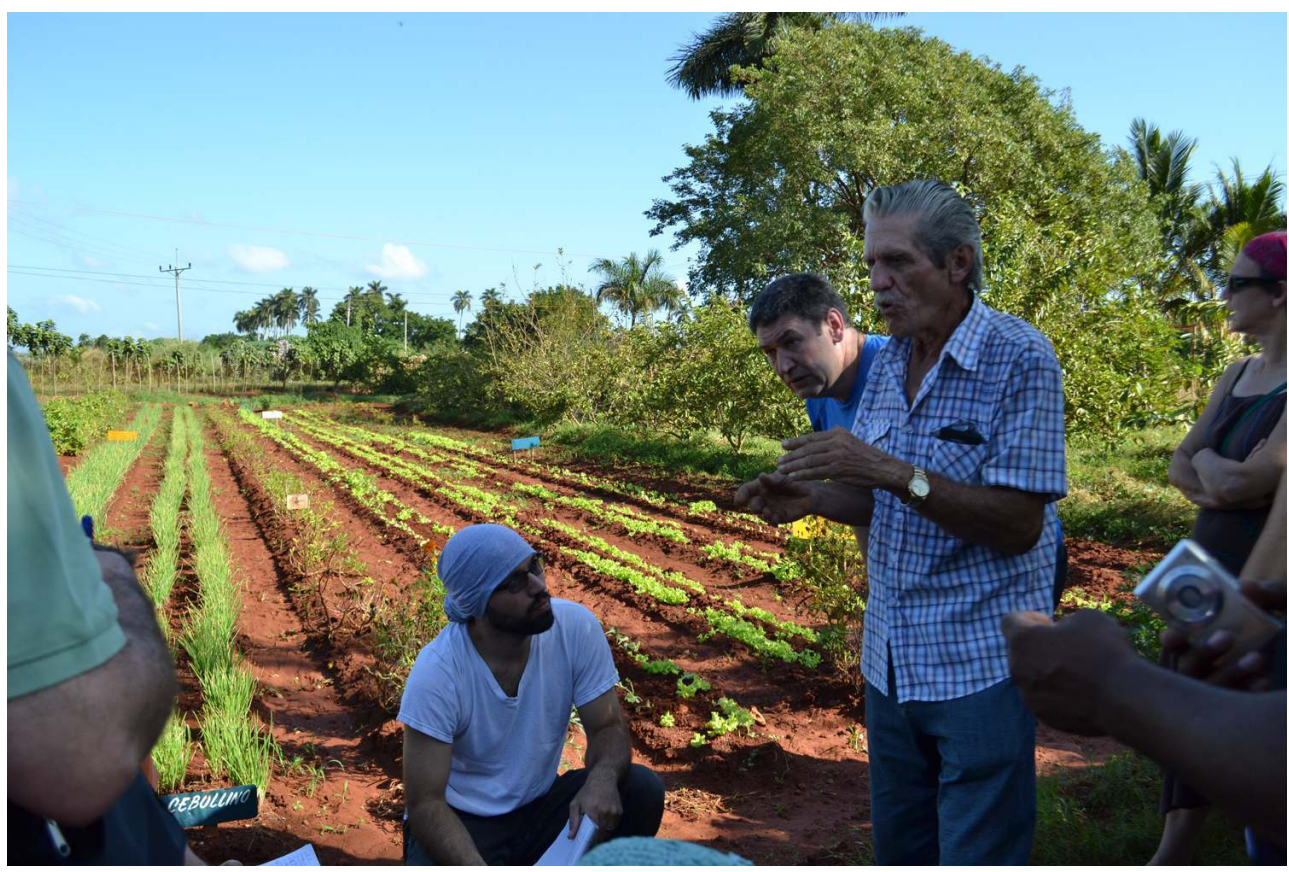

Un ejemplo de los beneficios de la asociación de cultivos, es la siembra de plátano (Musa sp. ABB) y malanga isleña (Colocasia esculenta (L.) Schott) en una misma parcela. Ambos cultivos requieren de mucha agua, mientras el plátano ofrece una sombra favorable para el cultivo de malanga. En caso de un ciclón tropical severo, las plantaciones de plátano se verían seriamente afectadas en su producción, mientras la malanga isleña, al tener el fruto bajo tierra, estaría en condiciones de recuperar follaje para ser cosechada posteriormente.

Foto 7. Asociación de plátano burro y malanga

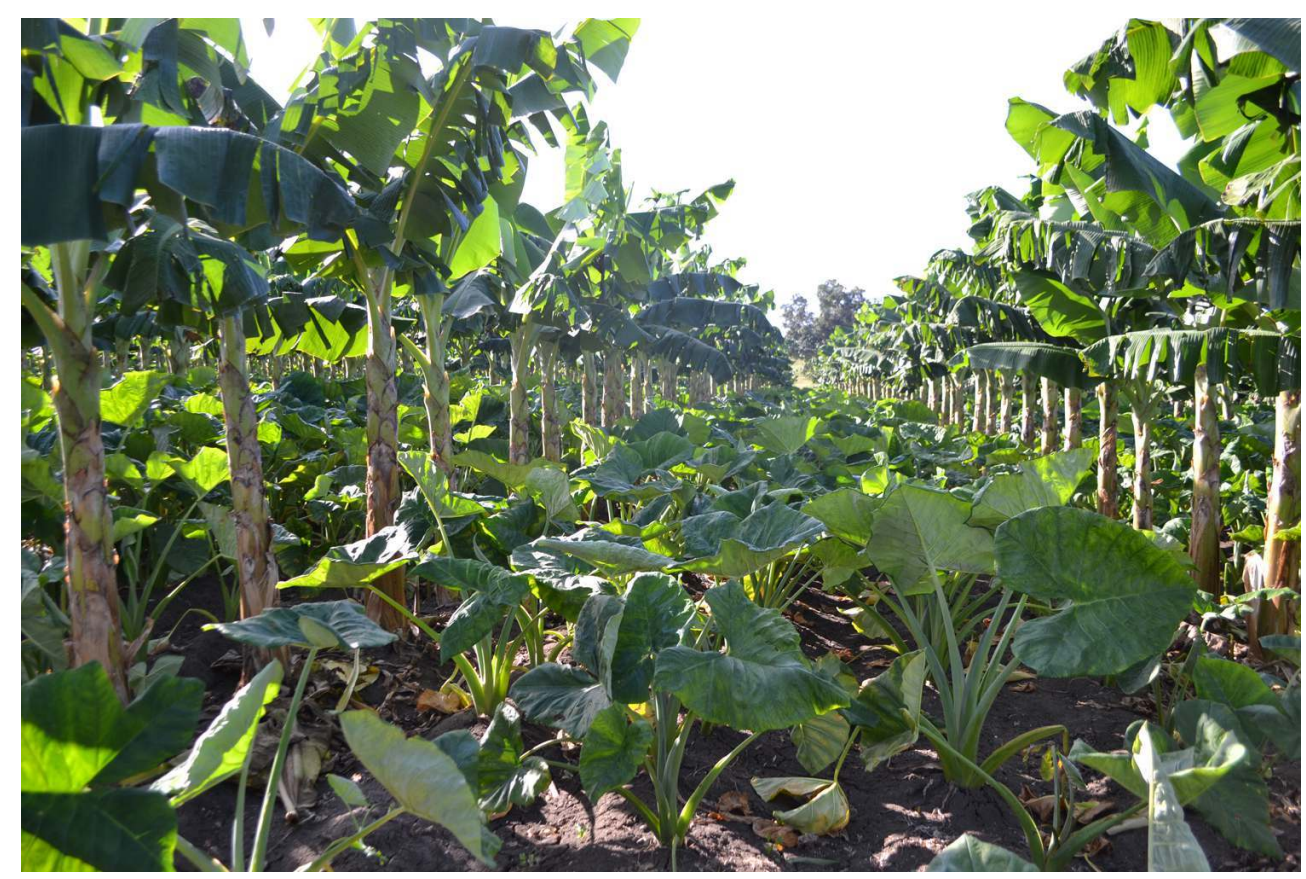



tracción animal. Para los productores, el arado con yunta de bueyes tiene un triple beneficio, por una parte no requieren de energía fósil, son ligeros, no compactan el suelo y permiten una mayor maniobrabilidad en parcelas en las que se va a cosechar diversos cultivos a lo largo del año y procuran abono orgánico.

Foto 8. Yunta de bueyes

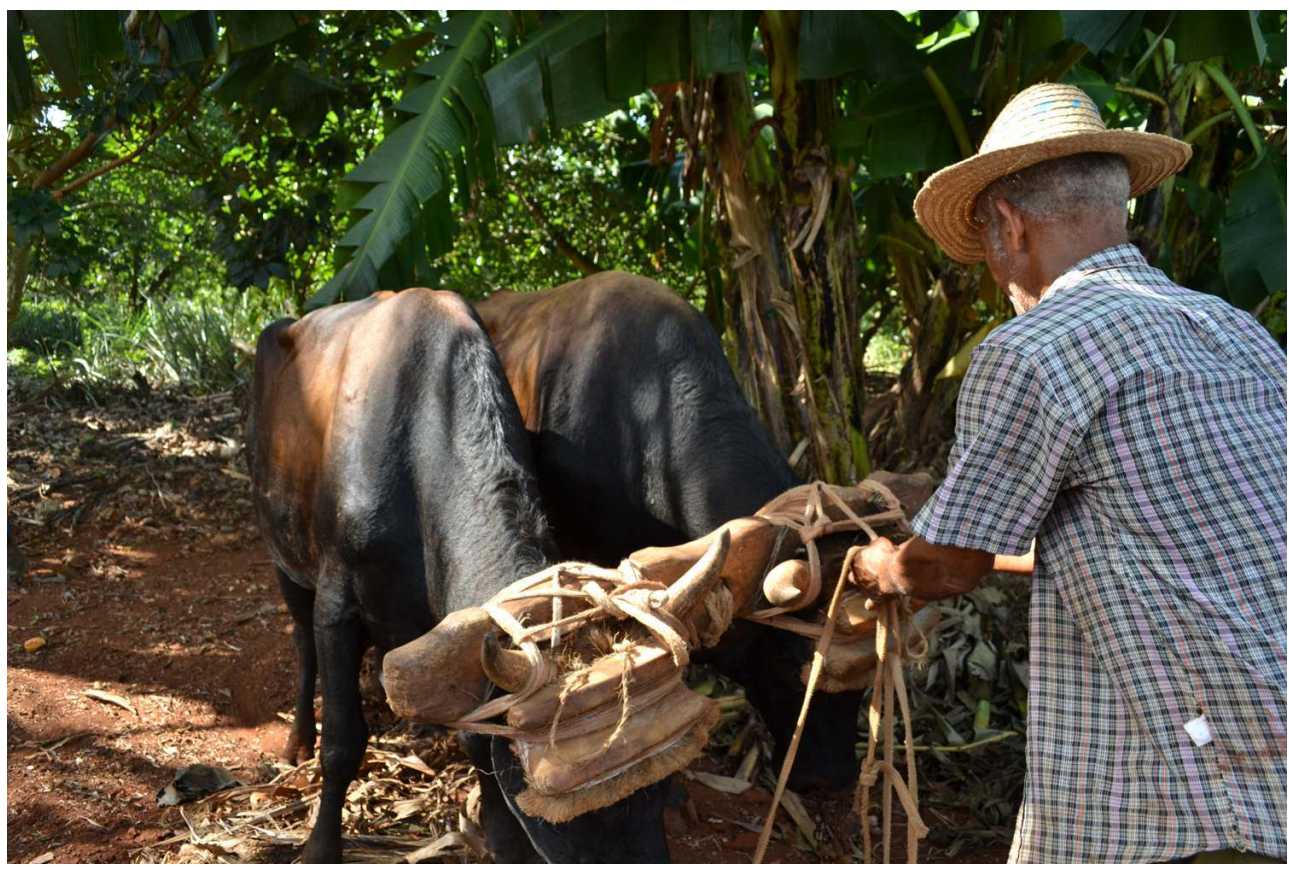

El gusto popular por una diversidad de viandas resulta un factor favorable para la seguridad alimentaria, ya que cada tipo de vianda requiere de condiciones distintas para su producción y almacenamiento. La yuca por ejemplo, resiste bien temporadas de sequía, pero un exceso de humedad afectaría de manera importante la producción. De manera opuesta, la malanga requiere de humedad para su buen desarrollo, la falta de riego o lluvia disminuiría su rendimiento. Ambos tubérculos, al igual que el boniato y ñame, tienen como almacén la parcela y se deben vender frescos, ya que se dañan si se les almacena por largo tiempo o si se ponen en refrigeración. En contraste, la papa demanda el uso de agroquímicos, es una producción semimecanizada (lo que implica el uso de energía fósil) y una inversión económica del $50 \%$ del gasto total solamente en la importación de semillas 9 . Pese a la inversión energética, los altos costos económicos y el hecho de que sólo se siembra y cosecha una vez al año (en invierno). La papa es un tubérculo que se puede almacenar por meses para liberarse al mercado cuando sea necesario (Martínez \& Alemán 2005). Por este motivo, la papa juega un papel importante en la seguridad alimentaria del país.

\section{Formas de acceder a las viandas}

Para los habitantes de Güira de Melena, el día domingo es la mejor oportunidad para conseguir una mayor variedad de productos. Desde muy tempranas horas, la Plaza Cívica se llena de camiones de gran tonelaje, carretas y tractores cargados de productos locales y de otras regiones. En este mercado, los guajiros ${ }^{10}$ tienen la oportunidad de comercializar 
sus excedentes y fijar sus propios precios. En este espacio comercial, no hay regulación de los precios y algunas veces hay intermediarios. Esto finalmente encarece los productos, los cuales suelen tener precios más elevados que en el agromercado.

Foto 9. Puestos ambulantes

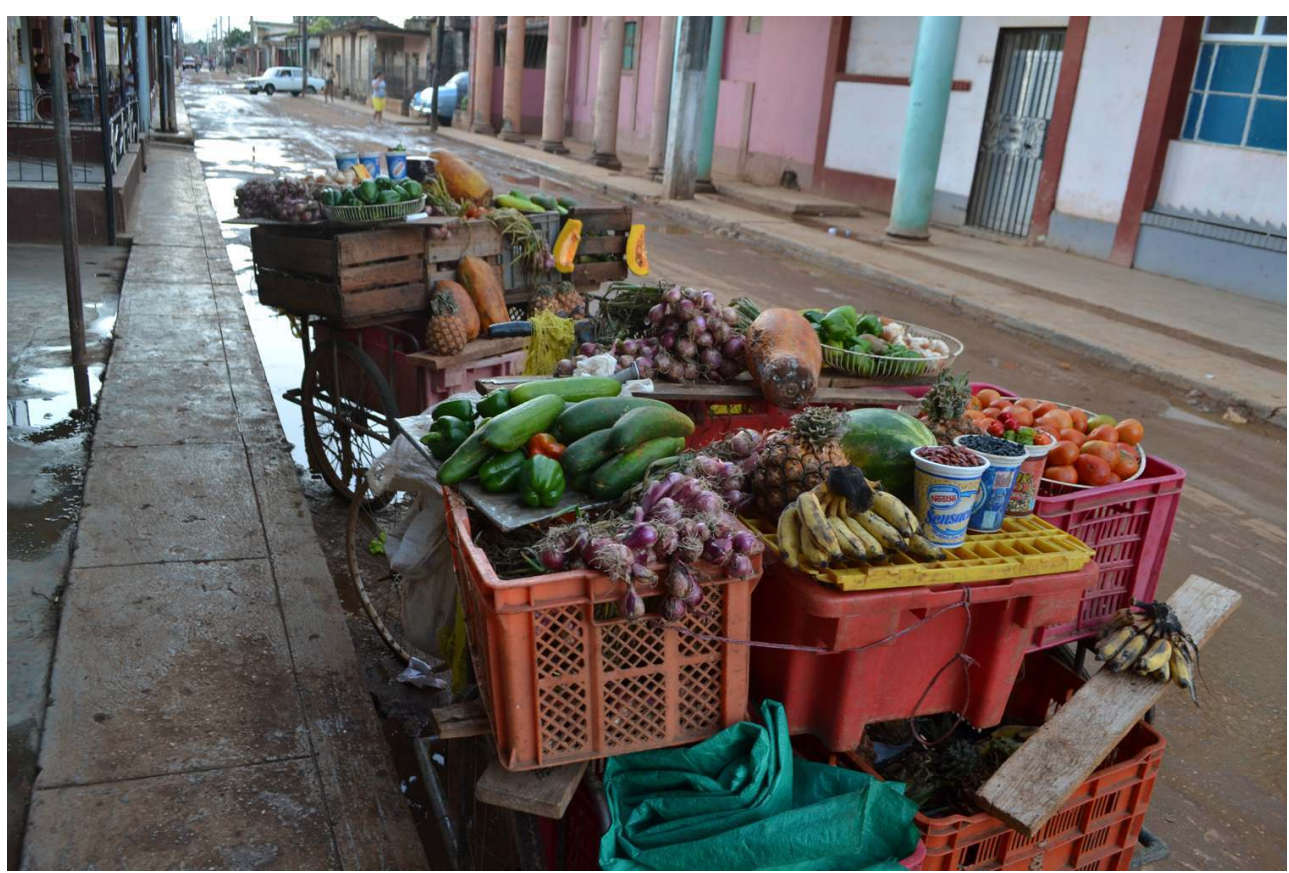

Foto 10. Agromercado

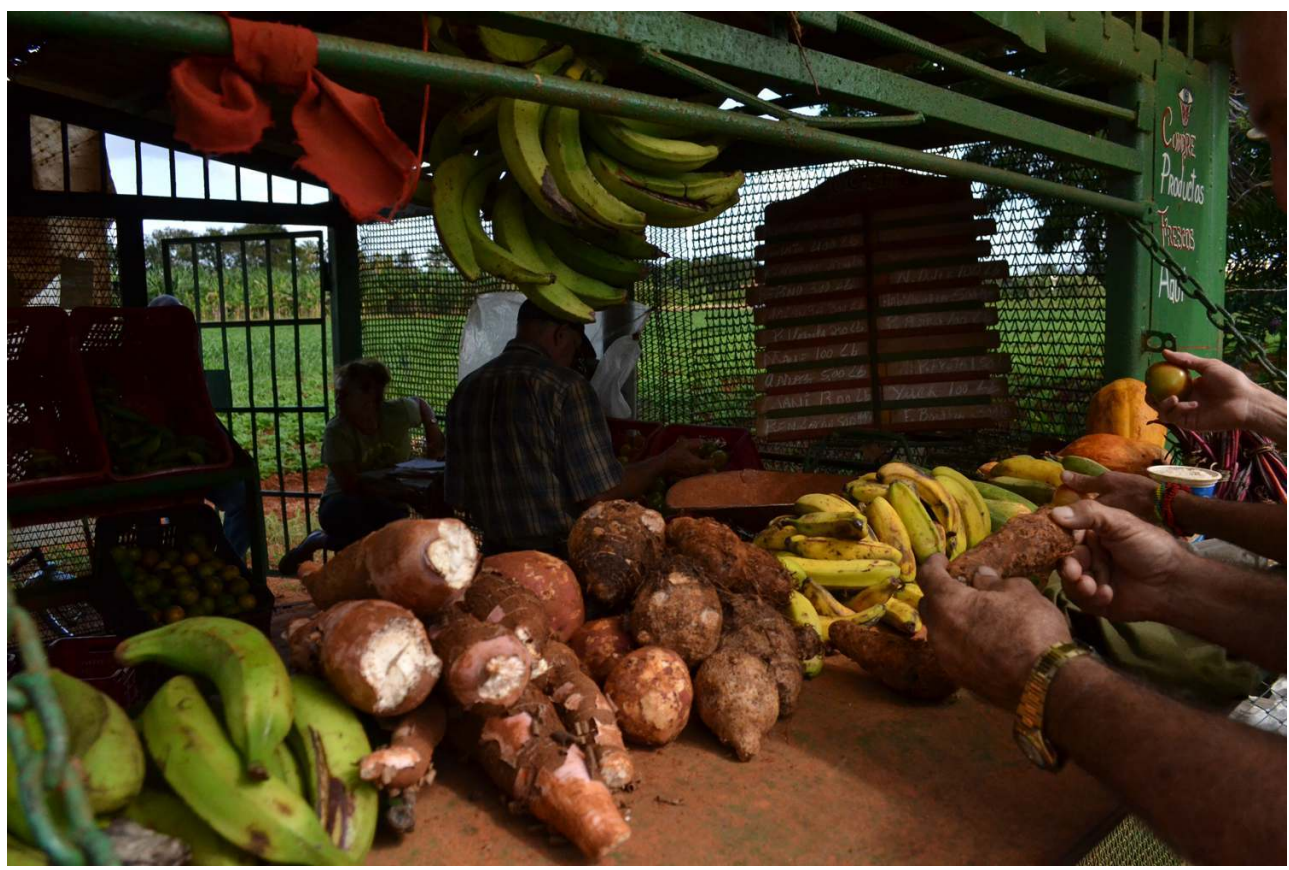

47 En Güira de Melena, se puede observar que el agromercado, desde tempranas horas comienza a recibir carretas con sacos de diferentes viandas y productos frescos. En nuestro recorrido etnográfico por distintos espacios comerciales, encontramos que la papa no estaba disponible ya que era tiempo de su siembra. Sin embargo, se podía 
encontrar diversos productos como malanga (Colocasia y Xanthosoma), boniato (Ipomoea), yuca (Manihot), dos tipos de plátano (Musa paradisiaca y M. sp. ABB), además de otras verduras, frutas y granos.

De manera contrastante, algunos entrevistados manifestaron que pocas veces compran estos productos. Esto gracias a que trabajan en el campo, o son miembros de alguna de las cooperativas de la región, o bien a que tienen familia (esposo o hijos) que trabajan en el campo y que con frecuencia llevan a casa costales de estos productos. Cuando hay excedentes, estos se comparten con los vecinos o con familiares. En casa de algunos entrevistados, también pudimos observar que en su jardín tenían una o dos matas de plátano burro, de las cuales pueden disponer cuando esté listo el producto.

Los entrevistados con situación económica más precaria y con un acceso a viandas más limitado fueron aquellos asalariados mayores de 50 años que no tienen un vínculo con el campo. Estos entrevistados manifestaron que, por lo regular, compran sus viandas en el agromercado. Cuando el dinero es insuficiente para comprar comida, la ración de alimentos que otorga el Estado (gratuitamente) es de gran ayuda, aunque algunos consideran que no es suficiente. Entonces, se tiene como una opción acudir con algún guajiro conocido para pedirle algunas viandas. Si la relación es muy cercana, por lo regular las regalan o se compran a un bajo costo.

Foto 11. Puestos ambulantes, frutas y viandas

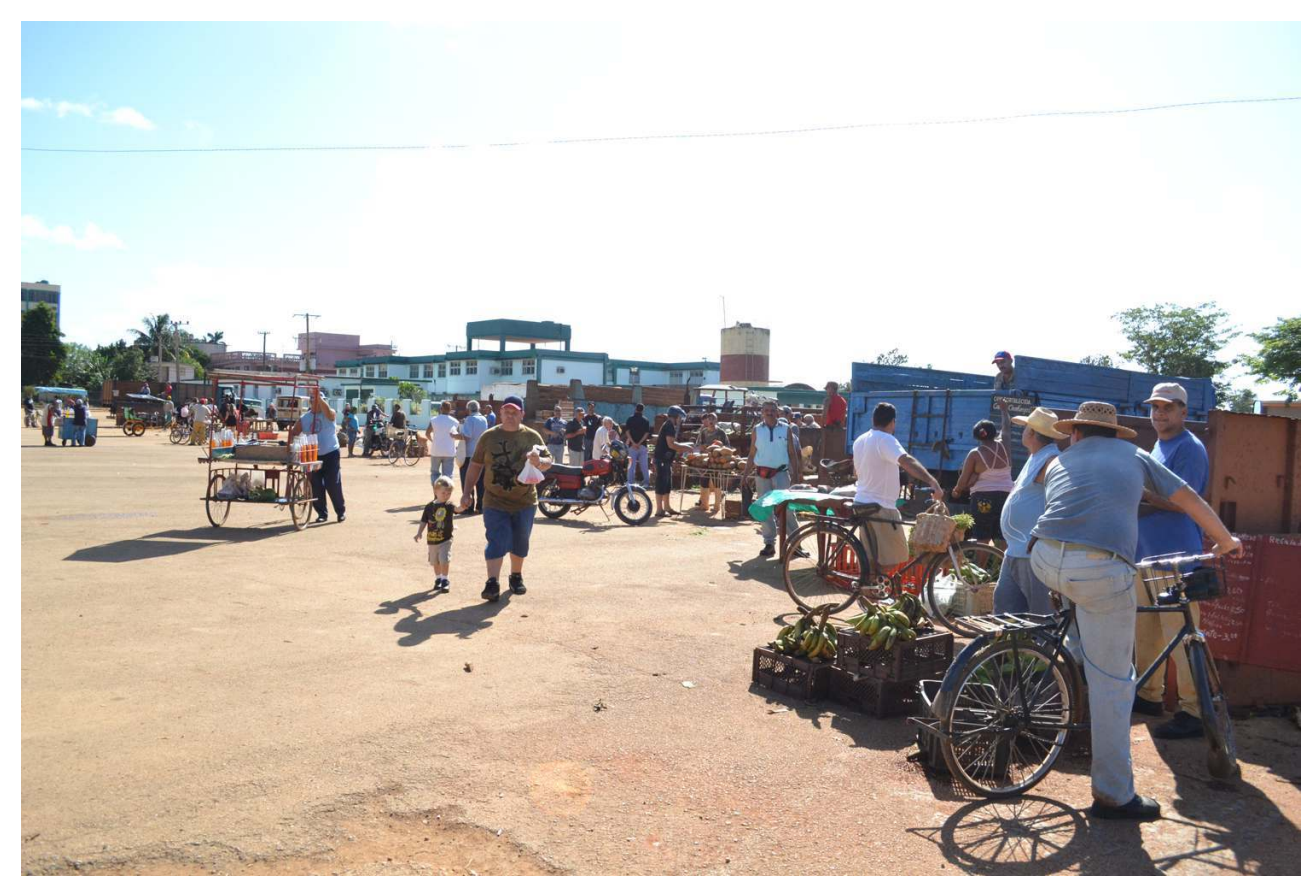

\section{Conclusiones}

El consumo de viandas tiene siglos de tradición en Cuba. Gran parte de su éxito como alimento es que ha sabido responder a las necesidades alimenticias de la población en distintos momentos históricos. Desde que la isla fue ocupada por los Españoles, las viandas nativas ofrecieron una fuente de energía que complementó la dieta, tanto de los conquistadores como de la gran población de esclavos quienes también sumaron sus saberes y gustos culinarios. Incluso en sucesos históricos más recientes, el consumo de 
este grupo de alimentos, continúa siendo dinámico, es decir, siguen surgiendo nuevas recetas y tradiciones en donde el consumo de las viandas tiene un lugar importante.

Consideramos que si bien durante la década de 1990, la producción de alimentos en Cuba se vió afectada por motivos políticos y económicos a nivel internacional, el principal factor de vulnerabilidad alimentaria fue el hecho de que su producción estaba sometida a un modelo agrícola intensivo y extensivo basado en insumos externos y enfocado a cubrir la demanda del mercado internacional. La revisión bibliográfica y los testimonios recabados nos dieron cuenta de lo vulnerables que son los cultivos en un esquema de producción extensiva de monocultivos. En estas condiciones, la producción de viandas (al igual que otros alimentos), mostraron su fragilidad al momento de dejar disponibles los insumos que permitían su reproducción en estas condiciones. Ante la crisis, el saber campesino tradicional y la rápida reacción del Estado para rediseñar su sistema nacional de producción de alimentos, permitió una pronta recuperación de la producción de alimentos básicos tales como las viandas, ganado menor y otros alimentos frescos.

En esta época de crisis, la población tuvo que encontrar la manera de resistir el tránsito de un modelo de producción intensivo (que respondía a las demandas del mercado internacional), a un sistema de producción diversificado y de bajos insumos enfocado a abastecer la demanda interna de alimentos. Este lapso de transición llegó a buen término, gracias a la capacidad de organización y capacitación, tanto de las instituciones estatales, como de la población, facilitando una reacción rápida para implementar sistemas alternativos para producción de alimentos destinados al autoconsumo. Con ello se modificaron diversos hábitos alimenticios de la población, incluyendo la incorporación de nuevos alimentos.

53 El estudio de caso de Güira de Melena, nos permitió conocer las alternativas que la población fue tejiendo para sobrevivir a una de las crisis de alimentos más difíciles y de mayor escala experimentada por un país latinoamericano. La experiencia de nuestros entrevistados nos mostró lo estrecha que es la relación entre las personas y sus alimentos y como esta relación está fuertemente determinada por factores que sobrepasan el ámbito de lo cuotidiano y lo local. Lo que pasa a nivel internacional afecta la producción en la parcela y lo que pasa en la parcela afecta también lo que pasa en la mesa de los hogares.

Asímismo la información recabada, nos ha permitido acercarnos brevemente al conocimiento local sobre las viandas, sus formas tradicionales de preparación, uso y comercialización. Los datos obtenidos nos dieron elementos para afirmar que un cambio en los sistemas productivos y la búsqueda de cultivos alternativos, finalmente afectan los hábitos alimenticios de las personas quienes buscan adaptar sus dietas a los alimentos disponibles en tiempos de crisis. El caso más claro lo pudimos observar con la incorporación del "plátano burro" (Musa sp. ABB) a la dieta popular. El gusto por esta nueva variedad de plátano solo fue posible a partir del desbasto de otras variedades de plátano; pese a ello, ahora forma parte del gusto y la cocina popular de los habitantes de Güira de Melena.

Asímismo pudimos apreciar el valor culinario y aprecio que tienen las personas por las distintas variedades de vianda. Sus diferentes usos que van desde alimento para bebés, remedio estomacal, alimento familiar, comida de mascotas o animales de engorda, hace de las viandas un grupo de alimentos relevante que toma su expresión social más concreta con la tradición culinaria popular de "la caldosa". Esta tradición muestra que, para el Cubano el consumo de viandas esta históricamente vinculado con su cultura 
alimentaria, por ello su paladar tiene la capacidad de adaptarse a nuevas variedades de viandas, sin dejar la esencia de las formas tradicionales de preparación en la cocina cubana contemporánea.

\section{BIBLIOGRAFÍA}

Fornet Piña F. 2007 - Diccionario gastronómico cubano. La Habana, Lic. Ma Luisa Acosta Hernández.

Funes F.M. 2009 - Agricultura con Futuro : la alternativa agroecológica para Cuba. Matanzas Cuba, Estación Experimental Indio Hatuey.

Funes-Monzonte F. 2001 - El movimiento cubano de agricultura orgánica. In Funes F., García L., Bourque M., Pérez N. \& Rosset P. (Ed.). Transformando el campo cubano : Avances de la agricultura sostenible. La Habana Cuba, ACTAF : 15-37.

Galván T.J. 2008 - Bailar bembé : una perspectiva antropológica procesual (Contramaestre, Santiago de Cuba). Revista de Indias 68 (243) : 207-240.

García A. 2001 - Santo, seña y ruta histórica del plátano hasta Cuba. Revista de Indias 61 (221) : 141-166.

González L., Ramírez T., Rodríguez S., Román M., Hernández M., Beovides Y., Gálvez J. \& Reinaldo E. 2009 - Características morfo-agronómicas de genotipos de plátanos (Musa spp.) pertenecientes al banco de Germoplasma del INIVIT. Centro Agrícola 36 (2) : 31-39; disponible en : http:// cagricola.uclv.edu.cu/descargas/pdf/V36-Numero_2/cag062091669.pdf consultado en Enero 2013.

Guerra S. \& Maldonado A. 2009 - Historia de la revolución cubana. Editorial Txalaparta.

Instituto de Suelos 2001 - Programa Nacional de lucha contra la desertificación y la sequía. La Habana Cuba, Editorial IS : 18 .

Katz E. 2009 - Emigración, transformaciones sociales y cambios culinarios en la Mixteca Alta (Oaxaca, México). Anthropology of food S6, Déc.

Machín B., Roque M., Ávila D., Rosset P. 2011 - Revolución agroecológica. El movimiento campesino a campesino de la ANAP en Cuba. La Habana Cuba, ANAP.

Martínez C. \& Alemán R. 2005 - Papa (Solanum tuberosum Sw.), cosecha, beneficio, y almacenamiento. Caso cubano, Centro Agrícola, 32 (3).

Maza N., Morales A., Ortiz O., Winters P., Alcázar J., Scott G. 2000 - Impacto del manejo integrado del tetuán del boniato (Cylas formicarius) en Cuba. La Habana, Cuba, Instituto de Investigación en Viandas Tropicales, Centro Internacional de la Papa.

Miranda M. P. (com) 2003 - Cuba : reestructuración económica y globalización. Bogotá Colombia, Centro Editorial Javeriano.

Núñez N. \& González E. 1999 - Antecedentes etnohistóricos de la alimentación tradicional en Cuba. Revista Cubana Aliment Nutr. 13 (2) : 145-50. 
ONE (Oficina Nacional de Estadísticas) 1997 - Principales indicadores del sector agropecuario. La Habana. Agosto : 30 .

ONE (Oficina Nacional de Estadísticas) 2010 - Anuario estadístico Güira de Melena, disponible en : http://www.one.cu/aed2010/02La\%20Habana/Municipios/17\%20Guira\%20de\%20Melena/esp/ Index.htm Consultado en Abril de 2012

Ortiz F. 1924 - Glosario de afronegrismos. La Habana, Cuba, Siglo XX.

Pérez J., Albert D., Rosete S., Sotolongo L., Fernández M., Delprete P. \& Raz L.

2005 - Consideraciones etnobotánicas sobre el género Dioscorea (Dioscoreaceae) en Cuba. Ecosistemas 14 (2) : 142-149.

Pérez R. 1999 - La ganadería cubana en transición. Revista Mundial De Zootecnia 92-1999/1

Reyes G.V. \& Martí S.N. 2007 - Etnoecología : punto de encuentro entre naturaleza y cultura. Ecosistemas 2007/3

Reyes Gavilán M. A. \& Moenck 1923 - Delicias de la Mesa. Manual de Cocina y Repostería. La Habana, Avisador Comercial.

Souza A. \& Da Silva J. 2006 - Management of plant species for controlling pests, by peasant farmers at Lagoa Seca, Paraíba state, Brazil : an ethnoecological approach. Journal of Ethnobiology and Ethnomedicine $2: 42,5 \mathrm{p}$.

Toledo V. 1990 - La perspectiva etnoecológica. Cinco reflexiones acerca de las "ciencias campesinas" sobre la naturaleza con especial referencia a México. Ciencias 4 : 22-29.

Toledo V. 1992 - What is ethnoecology? Origins, scope and implications of a rising discipline. Etnoecología 1 (1) : 5-21.

Toledo V. \& Barrera-Bassols N. 2009 - A etnoecologia : uma ciência pós-normal que estuda as sabedorias tradicionais. Desenvolvimento e Meio Ambiente 20 : 31-45. Editora UFPR

Waizel J. 2009 - El uso tradicional de las especies del género Dioscorea. Revista de Fitoterapia, 9 (1). Disponible en : http://www.fitoterapia.net/revista/pdf/RDF\%209.1_DIOSCOREA.pdf consultado en Enero 2013.

Wright J. 2009 - Sustainable agriculture and food security in an era of oil scarcity : lessons from Cuba. London, Earthscan.

\section{ANEXOS}

Glosario

Agromercado : Espacio de comercialización en donde se pueden encontrar granos, semillas y productos frescos.

Ajiaco : Sopa de viandas, carne y maíz, típica de los guajiros de Cuba.

Buñuelo : Postre popular que se prepara a partir de yuca y malanga cocidas, molidas y amasadas con huevo, anís, sal y harina hasta formar una masa que después será freída en pequeñas figuras. Se sirven con almíbar.

Caballería : En Cuba, es una medida agraria que equivale a 13.420 ha. 
Caldosa : Plato popular de carácter festivo, que se elabora improvisando fogones y grandes ollas para la elaboración de un caldo que contiene distintos tipos de carne (cerdo y pollo), plátano, boniato, yuca, calabaza, especias y agua.

Chicharrita : se prepara con viandas cortadas en rodajas finas, las cuales se fríen hasta que estén crujientes.

Congrí : Arroz guisado revuelto con frijoles negros o rojos.

Fricasé : Guisado de pollo (o cualquier otra carne), papas, verduras y especies.

Flan : Postre de calabaza. Se prepara con calabaza hervida (sin cascara), Mezclada con agua, leche, sal y canela (previamente hervidos). La mezcla se licua y se pasa por un colador fino, en seguida se pone a cocinar revolviendo constantemente hasta que se espese. Ya frío se sirve en trozos bañados en caramelo.

Fufú : Platillo elaborado con plátano, el cual primero es hervido en agua con sal y jugo de limón, después se fríe a fuego lento en una sartén, en donde es machacado junto con cebolla, ajo y pimienta.

Guajiro : Campesino cubano.

Malarrabia : El boniato se corta en cuadros, se pone a hervir en agua, se le agrega azúcar, canela, clavo de Castilla y cacahuate al gusto, se deja cocer. Una vez hecha miel la azucar se retira del fuego.

Mojo o mojito : Preparado con ajo, cebolla y sal, sofritos en aceite, luego mezclado con vinagre, limón o naranja agria. Se utiliza para dar sabor a las viandas hervidas.

Orishas : Divinidad hija y manifestación directa de Olóòrun (o Dios). Los Orishas son equivalentes a los santos católicos, intermediarios entre dios y los hombres. Algunos Orishas múy venerados son : Sangó, Osun, Elegua, Yéwá, entre otros.

Potaje : Platillo de frijoles, viandas, especies y carne de cerdo.

Tostón : Plátano macho o plátano burro cortado en rodajas gruesas, que se pone en la sartén con aceite frío. Se dejan calentar y freír hasta que empiezen a dorarse, dándoles la vuelta. Se sacan las rodajas, se escurren en papel absorbente. Se aplasta cada rodaja hasta que quede finita y se vuelve a poner en la sartén, se dejan freír hasta que quede dorada y crujiente. Antes de servir se escurre bien el aceite y se pone sal.

Vudú : Religión de origen africano. Existen diversas variantes y expresiones a lo largo del Caribe y América del sur.

Yoruba : Religión afrocubana también conocida como Santería o Regla de Osha-Ifa

Fuentes : Entrevistas y Glosario de afronegrismos de Ortiz (1924)

\section{NOTAS}

1. Ese término de viandas, que viene del latin vivanda, significa, por lo general, una comida, los alimentos y productos alimenticios. En Cuba, ha tomado ese sentido espécifico de alimentos dados por diversas raíces y tubérculos tales como se exponen en este estudio (cf. Fornet Piña 2007). (nota del editor)

2. La explicación de vocabulario en cursiva se encuentra en el glosario anexo. 
3. Los diversos ajustes estructurales que debió enfrentar el país, permitieron que se conservaran las conquistas sociales conseguidas por la revolución en vez de sucumbir ante la presión política de Estados Unidos (Guerra y Maldonado 2009). Pese a la gravedad de la situación económica de Cuba, los Estados Unidos continuaron con sus medidas punitivas hacia la isla. Entre ellas en 1992 bajo el nombre de Ley de la Democracia Cubana, se negaba la autorización a que cualquier empresa norteamericana realizara negociaciones con la isla y la famosa Ley Helms-Burton aprobada en 1996 la cual buscó (entre otras cosas) desalentar las relaciones comerciales y la inversión extranjera en Cuba por parte de cualquier país que tenga relación comercial con los Estados Unidos.

4. La sigatoka amarilla, Mycosphaerella musicola Leach, es una plaga que afecta las zonas de cultivos bananeros en Los Caribes. Esta enfermedad produce manchas en las hojas evitando la fotosíntesis y la pérdida del fruto. Enfermedad causada por el hongo Mycosphaerella musicola que produce manchas en las hojas evitando la fotosíntesis y la pérdida del fruto

5. Para dar difusión a las formas de producción alternativas, se realizó todo un programa de capacitación técnica y asesoría para que las personas produjeran alimentos libres de agroquímicos para el consumo familiar o de la localidad. Los resultados a la fecha son contundentes, actualmente existen 383,000 fincas urbanas que suman 50 mil hectáreas de tierra, que anteriormente era tierra ociosa. La producción actual de este tipo de agricultura es capaz de abastecer entre el $40 \%$ y $60 \%$ o más de todos los vegetales frescos que se consumen en varias de las grandes ciudades de Cuba (Funes 2009).

6. Las limitantes a las que se enfrentaba este sector llevaron a que se diera preferencia a la reproducción de razas de ganado que fueran acordes a las posibilidades de alimentación de cada lugar. Así el cebú lechero y criollo fueron seleccionadas para su reproducción en regiones del país con condiciones difíciles, mientras toros Siboney y vacas lecheras Holstein, se reproducen en regiones con características que responden a su alta demanda de alimento (Pérez 1999).

7. Sin ahondar si es una vianda o no, el Instituto de Investigación en Viandas Tropicales de Cuba (IIVT), mantiene a la calabaza al igual que otras hortalizas y frutas dentro de sus líneas de investigación, debido a su importancia en la alimentación de la población en general.

8. Si bien los entrevistados mencionaron que la calabaza es preferida en postre, en una revisión de recetas tradicionales, se encontró que existen manuales de cocina cubana de principios del siglo XX que incluyen una variedad de recetas de cocina para preparar la calabaza de distintas formas. En el manual de cocina cubana más famoso "Delicias de la Mesa. Manual de Cocina y Repostería" de María Antonieta Reyes Gavilán y Moenck de 1925, se describen algunas recetas donde el elemento central es la calabaza.

9. Entrevista a Sergio Rodríguez Morales director del Instituto Nacional de Investigaciones de Viandas Tropicales (INIVIT), publicada en el Diario Granma, La Habana, viernes 16 de marzo de 2012. Año 16 / Número 74 http://www.granma.cubaweb.cu/2012/03/16/nacional/artic06.html 10. Recientemente, el gobierno decretó que una vez cubierta la cuota de comercialización con el Estado, los excedentes de producción, podían ser comercializados directamente al consumidor a precios de oferta y demanda. Esta posibilidad de comercializar excedentes no sólo estimula el incremento de la producción, sino que también permite que los guajiros o productores, puedan incrementar su ingreso económico de manera importante, haciendo de la actividad agrícola una de las labores más rentables y atractivas. 


\section{RESÚMENES}

La cultura gastronómica de cada sociedad es la forma en que históricamente los grupos sociales, clasifican, valoran y preparan los alimentos que consumen. Esta cultura alimentaria no es estática, y está en constante cambio. El presente trabajo pretende ejemplificar como en un mundo global los cambios sociopolíticos en sus diferentes escalas tienen efectos que trastocan la vida cotidiana, incluyendo el gusto por nuevos alimentos y con ello cambios en las tradiciones culinarias. Para ejemplificar esta tesis, tomamos el caso de Cuba, país que desde mitad del siglo pasado, ha enfrentado importantes transformaciones políticas y sociales. El estudio de caso se realizó, en 2011, en el poblado de Güira de Melena, ubicado en la provincia de Artemisa (ver el mapa). El eje central de análisis fue el consumo de "viandas", término que integra un grupo de alimentos conformado por diversas raíces, tubérculos, rizomas, plátano y calabaza de los géneros Maníhot, Dioscorea, Ipomoea, Xanthosoma, Solanum, Colocasia, Musa y Cucúrbita. A excepción de la papa (Solanum tuberosum), las distintas variedades de viandas, están bien adaptadas a las condiciones climáticas del país, y todas ellas se consideran productos esenciales tanto de la gastronomía, como de la nutrición del pueblo cubano. Desde una perspectiva etnoecológicopolítica buscamos identificar la forma en que las personas clasifican y nombran las distintas viandas, según sus propiedades, usos y formas en que son preparadas, consumidas cotidianamente, tomando en cuenta los cambios en la producción y consumo de estos alimentos a partir de las transformaciones socio-económicas del país en las últimas décadas.

Hasta antes de finales de la década de 1980, Cuba destinaba el 50\% de su territorio cultivable a la producción intensiva y a gran escala de soló tres productos : azúcar, tabaco y cítricos, los cuales eran exportados a los países de la Unión Soviética a un precio favorable y a cambio de diversos insumos como petróleo, maquinaria agrícola y agroquímicos. Pese al potencial productivo de la isla, el ingreso por exportaciones se destinaba en gran medida a la importación del $57 \%$ de los alimentos básicos que necesitaba la población. Al desaparecer el bloque socialista, a principios de la década de 1990, desapareció también el principal mercado para los productos tropicales de exportación de Cuba. El bloqueo económico impuesto por los Estados Unidos impedía al gobierno cubano tanto las importaciones como el comercio con otros países, lo que profundizó la crisis alimentaria. La producción de alimentos al interior de la isla se desarrolló entonces en un contexto de bajos insumos agrícolas, altos índices de degradación del suelo y la presencia de plagas asociadas al sistema de producción intensivo que mantuvo la isla por décadas para cubrir la demanda de productos de exportación. Ante la falta de alimentos suficientes para la población, el gobierno impulsó, de manera urgente, políticas que estimularan la producción descentralizada y diversificada de alimentos, al mismo tiempo que se promovió la producción para el autoconsumo, tanto en las ciudades como en las zonas rurales. A este período de escasez de alimentos se le conoció como el "período especial". En este contexto, las "viandas" jugaron un papel importante para cubrir la demanda de calorías en la población, ya que era el único producto en el cual el país era autosuficiente. El estudio de caso del poblado Güira de Melena en la provincia de Artemisa, nos muestra como los pobladores, ante la perdida de algunas de las variedades tradicionales de viandas, tuvieron que incorporar nuevas especies a su dieta. Esto se ejemplifica con las variedades de plátano Musa paradisiaca y Musa nana, las cuales estuvieron al borde de la extinción debido a la afectación de la sigatoka amarilla, la cual ya no era posible 
controlar a través del uso de agroquímicos y aspersión aérea. En la búsqueda de alternativas, se introdujo al país la variedad de plátano Musa sp. ABB, la cual mostró ser resistente a la sigatoka y útil para cocinarse como vianda. Nuestro estudio de caso ejemplifica como, si bien al principio las características organolépticas de la Musa sp. ABB, no gustaba a los consumidores, la falta de opciones llevó a que poco a poco fuera ganando espacio en la cocina y el gusto de los Cubanos, al punto que, actualmente, de forma popular, se le conoce como "plátano burro" y se manifiesta como una de las viandas preferidas para acompañar el plato principal de la cocina cubana que es el arroz y frijol.

La culture gastronomique de chaque société parle de l'histoire dont les groupes classent, apprécient et préparent les aliments qu'ils consomment. Cette culture alimentaire est dynamique, elle change en permanence. Le présent travail veut montrer comment, dans un monde globalisé, les changements socio-politiques, à leurs différents niveaux, peuvent bouleverser la vie quotidienne, y compris le goût pour des aliments nouveaux; c'est ce qui entraîne les changements dans les traditions alimentaires. Pour exemple, on prend ici le cas de Cuba, pays qui depuis la moitié du siècle dernier, a dû confronter des transformations considérables tant politiques que sociales. Cette étude a été réalisée en 2011, dans le village de Güira de Melena, situé dans la province d'Artemisa (Voir carte). L'axe principal de cette analyse est la consommation des viandas (racines, tubercules, rhizomes, banane et courge), lesquelles, dans la majorité des cas, sont cultivées dans le pays et sont considérées comme des produits essentiels de la cuisine et de l'alimentation du peuple cubain. Par une approche ethnoécologicopolitique, on cherche à identifier le rôle qu'ont eu ces produits pour la sécurité alimentaire de Cuba, aussi bien dans la façon dont les personnes nomment et classent les différentes viandas (propriétés, utilisations, façons de préparer et consommation) et combien ils ont souffert des changements importants dans la production avec les transformations socio-économiques qu'a subi le pays, dans les dernières décennies.

Avant la fin des années $80,50 \%$ du territoire cultivé de Cuba était destiné à la production intensive à grande échelle de trois produits, canne à sucre, tabac et Citrus, exportés vers les pays de l'URSS à un prix favorable et en échange de divers produits tels le pétrole, les machines agricoles et les engrais chimiques. Malgré le potentiel productif de l'île, le revenu des exportations servait en grande partie à l'importation de 57\% des aliments de base nécessités par la population. À la disparition du bloc socialiste, au début des années 90, disparut également le principal marché des produits tropicaux d'exportation de Cuba, et le blocus économique imposé par les États Unis stoppait tout commerce extérieur, tant les importations que les exportations, ce qui a profondément aggravé la crise alimentaire. À l'intérieur de l'île, s'est alors développée une production alimentaire dans le contexte d'une agriculture avec peu d'intrants, une forte dégradation des sols, et le développement de pestes associées au système de production intensive, situation qui a maintenu l'ile pendant deux décennies dans la difficulté de répondre à la demande de produits d'exportation. Devant la pénurie alimentaire, le gouvernement a très vite lancé des politiques pour stimuler la production décentralisée et diversifiée de produits alimentaires, tout en promouvant la production de l'autoconsommation, aussi bien dans les villes, que dans les zones rurales. On a appelé cette période de pénurie alimentaire "période spéciale". Dans ce contexte, les "viandas" on joué un rôle majeur pour couvrir les besoins en calories, puisqu'elles étaient le seul produit où Cuba est autosuffisant. Le cas du village de Güira de Melena, dans la province d'Artemisia, montre comment la population, devant la perte de quelques variétés traditionnelles de viandas, durent incorporer de nouvelles espèces à leur alimentation. C'est l'exemple des variétés de bananes Musa paradisiaca et M. nana qui faillirent disparaître sous l'action du champignon Mycosphaerella musicola Leach, devenu incontrôlable sans insecticide ni aspersion aérienne. Recherchant des alternatives, on a introduit la variété Musa sp. 
$\mathrm{ABB}$, qui s'est révélée résistante au champignon et bonne pour la cuisine. Cette étude montre comment les qualités gustatives de Musa sp. ABB, mal perçues au début, se sont peu à peu, devant le manque d'alternatives, intégrées dans la cuisine cubaine à tel point qu'aujourd'hui on nomme cette banane "banane âne" et qu'elle est devenue l'une des viandas préférées pour accompagner le plat fétiche des Cubains, riz et haricots.

The food culture of a society is the way in which social groups have historically classified, valued and prepared their food. It is not static but is constantly changing. This paper aims to illustrate how the global socio-political changes at different levels have effects that disrupt daily life, including the taste for new foods and hence change culinary traditions. To illustrate this thesis, we focus on a case study done in Cuba, a country that since the middle of the last century, has faced major political and social upheavals. The study is of the village of Güira de Melena, located in the province of Artemisa. The focus of analysis was the use of "viandas", a term constituting a food group composed of various roots, tubers, rhizomes, banana and squash of the genuses Manihot, discorea, Xanthosoma, ipomoea, solanum, colocasia, musa y cucúrbita. Except for the potato (Solanum tuberosum Sw), the different varieties of viandas, are well adapted to the climatic conditions of the country, all of which are considered essential products both gastronomically and with respect to the nutrition of the Cuban people. Using a ethno-ecological perspective, we identify how people classifyand name the different meats, according to their properties, uses and manners of preparation. The case study considers how the changes in the production patterns of Cuban economy in recent decades have impacted the quantities consumed daily of the different products.

\section{ÍNDICE}

Mots-clés: ethnoécologie politique, viandas, agriculture durable

Palabras claves: etnoecología política, Cuba, viandas, agricultura sustentable

Índice geográfico: Cuba

Keywords: political ethnoecology, Cuba, viandas, sustainable agriculture

\section{AUTOR}

\section{NORMA HELEN JUÁREZ}

Maestra en Antropología Social y estudiante del programa de Doctorado en Ciencias de la Universidad de Guadalajara, México 